\title{
Source country culture and labor market assimilation of immigrant women in Sweden: evidence from longitudinal data
}

\author{
Emma Neuman $\mathbb{D}^{1}$
}

Received: 12 October 2017 / Accepted: 28 May 2018 / Published online: 22 June 2018

(C) The Author(s) 2018; This article is published with open access at Springerlink.com

\begin{abstract}
This paper analyzes the role of source country culture on gender roles for labor market assimilation of immigrant women in Sweden. Sweden ranks as one of the world's most gender-equal countries and at the same time a recipient of many immigrants from countries with more traditional views on gender roles and gender equality. I find that the labor force participation of immigrant women in Sweden is related to their source country culture, in the sense that women from countries where women's labor market participation is low (high) also have low (high) participation in the Swedish labor market. However, all immigrant women assimilate towards, but do not reach parity with, the participation rate of native women, and the difference between women from high- and low-participation countries diminishes with length of residence in Sweden. This indicates that source country culture on gender roles does not have a persistent effect on immigrant women's labor market participation in Sweden. Furthermore, the results highlight the importance of taking into account unobservable time-constant individual and source country factors when estimating the relationship between source country culture and immigrants' labor market outcomes. Neglecting to control for these factors could lead researchers to misrepresent the rate of assimilation and overstate the effect of source country culture.
\end{abstract}

Keywords Source country culture $\cdot$ Gender norms $\cdot$ Immigrant assimilation $\cdot$ Labor market participation

JEL-classification $\quad \mathrm{J} 15 \cdot \mathrm{J} 16 \cdot \mathrm{J} 22 \cdot \mathrm{J} 31$

Emma Neuman

emma.neuman@1nu.se

1 Department of Economics and Statistics and Centre for Discrimination and Integration Studies,

Linnaeus University, SE-351 95 Växjö, Sweden 


\section{Introduction}

The creation of a strong and functional labor market is at the heart of individual and societal welfare. Central to this process is ensuring equal opportunities to participate in the labor market work and earn a fair wage. Despite some progress, in most countries men still outnumber women in the labor market. In addition, advancements in gender equality spread unevenly around the world and therefore gender disparities in labor force participation (LFP) vary greatly. Sweden ranks as one of the world's most gender-equal countries (Hausmann et al. various years) and is at the same time a recipient of immigrants from countries with more traditional views of gender roles and gender equality. In Sweden the LFP rate of women in 2016 is about eight percentage points below that of men, while in countries such as Afghanistan and Syria the difference is around 60 percentage points (International Labor Organization). Furthermore, the participation rate of immigrant women in Sweden is about 10 to 15 percentage points below that of native women, and only about half of the loweducated immigrant women participate in labor market work (Statistics Sweden 2016). This brings to the fore the question of whether the LFP of immigrant women in Sweden continues to be shaped by more traditional gender roles and a less equal division of labor in their source countries, or if their LFP comes to resemble that of native Swedish women with the passage of time since migration.

There is a large literature on labor market assimilation of immigrants in the host country (e.g., Borjas 1995 for the United States; Edin et al. 2000 and Hammarstedt 2003 for Sweden). ${ }^{1}$ This literature shows that new immigrants tend to be at a labor market disadvantage, but this disadvantage decreases with time in the host country. To date, researchers have not fully explored the gender disparities and the impact of source country factors in the assimilation process. In this paper, I investigate the extent to which a traditional culture - one with a more traditional view of gender roles - in the source country is important for immigrant women's labor market assimilation to that of comparable native women in Sweden.

The economic literature defines culture as the totality of differences in beliefs and preferences across groups with different cultural backgrounds (Fernández 2007). I follow previous literature and measure source country cultural beliefs regarding the appropriate role of women by the source country female relative LFP (FLFP). The FLFP is the female LFP rate divided by the male LFP rate (e.g., Antecol 2000; Blau et al. 2011; Blau 2015; Blau and Kahn 2015). This measure captures the source country's culture on gender roles, and affects immigrant women's LFP in the host country through the preferences and/or learned beliefs regarding women's labor supply behavior and the household division of labor in her source country (see e.g., Fernández 2007, 2008, 2011). I will answer the following research questions. Are immigrant women from countries with high FLFP rates engaged in labor market work to a higher degree than immigrant women from countries with low FLFP rates? Is the difference between immigrant women from high- and low-participation countries constant, increasing, or decreasing as length of residence in Sweden

\footnotetext{
${ }^{1}$ In this paper, assimilation is the process by which immigrants' labor force participation converges with that of natives with passage of time in the host country. The terms assimilation and labor market assimilation will be used interchangeably throughout the paper.
} 
increases? Does immigrant women's participation in the labor force reach that of native women with passage of time since migration? Blau et al. (2011) argue that if differences in labor market participation between immigrant women from countries with high and low FLFP persist with time in the host country, this indicates that culture has an important effect on gender roles. Should all immigrant women, independently of FLFP, assimilate to the participation rates of comparable natives, this indicates that the host country's culture, institutions, and economic environment might be more important than those of the source country's culture. In other words, immigrant women's labor market assimilation could be driven both by adjustments to a new institutional environment and/or by changes in their culture on gender roles to be more in line with that of natives. Separating these mechanisms is outside the scope of this paper.

For the United States, research has shown that immigrant women from countries with low FLFP rates work less than do immigrant women from countries with high FLFP, but that both groups assimilate towards the work hours of comparable native women (Blau et al. 2011; Blau 2015; Blau and Kahn 2015). If and how these results translate to other countries is still unknown. Compared to the United States, Sweden offers more and farther-reaching gender-specific institutions, such as parental leave and child-care facilities, and a larger percentage of women participates in labor market work (e.g., Anxo et al. 2011; Blau and Kahn 1996; Rønsen and Sundström 2002; Ruhm 1998). Hence, I investigate whether source country culture on gender roles is transmitted and explains immigrant women's labor market participation in a society that emphasizes gender equality and women's participation in labor market work more than the United States.

To study the association between FLFP and immigrant women's labor market participation, I use Swedish longitudinal register data covering the full Swedish population from 1990 to 2007, together with source country data collected around the time of migration. Apart from extending the literature to the Swedish case, the longitudinal data allows us to make additional contributions. In the previous literature on culture and immigrant's outcomes, the main challenge has been to separate the effect of source country culture from that of other source country variables (e.g., women's education and skills) and selection in migration. I use a model with individual-fixed effects, implying that the bias of the assimilation estimates from time-constant individual and source country factors and return and onwards migration is reduced. In previous literature it has been hard to rule out that the rate of assimilation is connected not only to culture, but also to the likelihood of return migration. Moreover, I will follow previous literature and examine the behavior of immigrant men, which can serve as a falsification test (Blau 2015). If the source country FLFP has the same impact on immigrant men and women's participation rates, this indicates that the source country's FLFP captures other omitted source country variables.

Our results show that immigrant women arriving in Sweden in the 1980s and 1990s have lower LFP rates than comparable native women at arrival, and that this disparity reduces with time spent in Sweden. Furthermore, immigrant women from countries with high FLFP rates have between 3 and 17 percentage points higher participation rates than do women from countries with low FLFP. These results point in the direction that the source country culture on gender roles is important for 
immigrant women's labor market behavior in their new host country. However, the results seem to be driven partly by differences in individual characteristics and return migration between immigrants from low- and high-participation countries. Still, among immigrant women arriving to Sweden in the 1990s, those from highparticipation countries work more than women that migrated from low-participation countries. However, neither women from high-participation countries nor those from low-participation countries assimilate to the participation level of native women. Furthermore, source country female relative participation is not strongly correlated with immigrant men's labor market participation in Sweden. This supports the idea that the source country LFP captures source country culture on gender roles rather than other omitted factors, such as work behavior, that affect men and women similarly.

The remainder of the paper is organized as follows. "Literature review" section offers an overview of the literature. "Data and descriptive statistics" section presents the data and descriptive statistics. "Empirical specification" section presents the empirical model and "Results" section explains the results. Finally, "Conclusions" section concludes.

\section{Literature review}

Research has shown that women tend to have lower earnings and labor market participation rates than men (e.g., Blau and Kahn 1996, 2000; Albrecht et al. 2003). Some of these gender gaps in labor market outcomes remain unexplained even after controlling for individual differences in education and experience. Among the reasons for these differences, the literature has suggested norms and attitudes about gender roles, productivity differences, and discrimination.

Becker (1985) argues that women's higher responsibility for family and household work might lead to lower labor market participation and discourage women from investing in their human capital. Furthermore, women might put less effort into market work than men because of the greater number of hours they spend on household work, which depresses their productivity and wages (Becker 1985). Moreover, it is possible that women earn lower wages because of discrimination in the labor market. Becker's (1957) model attributes labor market discrimination against women to discriminatory tastes expressed by employers, customers, and/or co-workers. Another possibility is that discrimination results from employers' expectation that female employees are less productive than their male co-workers (e.g., Aigner and Cain 1977).

Furthermore, it is has been suggested that gender gaps in labor market outcomes, rather than being related to the demand-side of the labor market, are explained by supply-side related factors. For Sweden, Carlsson (2011) provides evidence that occupational segregation by gender in the labor market seems to be driven by employees' own preferences, not by employer discrimination. Furthermore, in Scandinavia the expansion of the welfare state was a factor in women's increased labor market participation, but the expansion also led to increased gender occupational segregation with many women working in the public sector (Esping-Andersen 1990). In addition, women's occupational choices might be influenced by gender 
stereotypes (England 1992; Charles and Grusky 2004). In other words, women might choose low-wage occupations or not to work at all because of norms and attitudes about their role in the labor market. Numerous studies have investigated whether the beliefs, attitudes and social norms about gender, usually referred to as culture, contribute to gender gaps, by comparing outcomes for women in different countries and cultures. For instance, in a cross-country study, Albrecht et al. (2000) show that if women believe that mothers should work full-time, they are more likely to work full-time themselves. Fortin (2005) draws a similar conclusion: in countries where women are perceived mainly as homemakers, women tend to have worse labor market outcomes. This suggests that culture's effect on gender roles is important for women's labor market behavior.

However, a major drawback with cross-country studies is that they neglect to control for institutional differences across countries, such as child-care and parental leave policies, which might be correlated both with culture on gender roles and women's labor market outcomes. To avoid bias from institutional differences, the role of culture has been investigated by comparing immigrants: people within the same labor market who have different cultural backgrounds. In the literature, this is known as the epidemiological method (Fernández 2008) and has been used to study the impact of culture on a variety of outcomes. ${ }^{2}$ The premise is that immigrants differ in terms of their culture on gender roles, but share the institutional setting and economic environment in their new host country. Antecol $(2000,2001)$ shows that cultural factors explain part of the inter-ethnic variation in gender gaps in wages and LFP across immigrant groups in the United States. Similarly, Blau et al. (2011) find that immigrant women who have migrated from countries with high FLFP rates work more than do immigrant women from countries with low FLFP rates. To the best of my knowledge, Bredtmann and Otten's (2013) study is the only one that expands the literature on the association between culture and gender gaps in immigrants' labor market outcomes to a European context. Bredtmann and Otten (2013) use survey data from the European Social Survey 2002-2011 and find a positive correlation between host-country female LFP and source country female LFP. Hence, the literature is still scarce and the extent to which the relationship between source country culture on gender roles and immigrant women's labor market outcomes observed in the United States holds in other contexts still merits investigation.

Thus, previous literature suggests that the source country culture on gender roles continues to shape immigrants' behavior in their host country. This is in line with economic theory stating that females' attitudes toward traditional gender roles, formed early in life and later shaped by societal attitudes, influence their labor supply decisions (Fortin 2005; Vella 1994). As pointed out by Blau (1992) it is reasonable to believe that the cultural climate in which women have been brought up is likely to affect their post-migration behavior. As a result, outcomes among immigrants are likely to differ from outcomes among natives. From a theoretical point of view, the influence of the source country culture on gender roles is expected to be greater on married women, since traditional gender roles are likely to be more detrimental for labor supply decisions within the household (Blau 2015; Blau et al. 2011). However, previous literature finds that culture on gender roles, measured by the source country

\footnotetext{
2 For an overview see for instance Fernández (2011).
} 
FLFP, has a similar effect on married and single women (Blau 2015; Blau et al. 2011). This suggests that culture on gender roles affects not only the household division of labor but also the single women's preferences for working.

To date, few studies have investigated whether the impact of source country culture on gender gaps remains or diminishes with the passage of time since migration. Blau (1992) argues that the longer an immigrant remains in the new host country, the more his or her differences from natives will diminish as behavior adjusts to the economic and social conditions in the new country. Several studies have shown that cultural factors continue to shape labor market behavior, educational outcomes, and non-market work among second-generation immigrants, but the impact tends to be smaller than for first-generation immigrants (e.g., Antecol 2000; Blau et al. 2013; Eylem Gevrek et al. 2013; Fernández and Fogli 2009; Hwang 2016; Nollenberger et al. 2016; Finseraas and Kotsadam 2017).

A more direct way to study the possible diminishing impact of source country culture on gender roles is to investigate the extent to which first-generation immigrant women from different source countries assimilate to the LFP of comparable native females. Blau et al. (2011) argue that if differences in LFP among immigrant women from countries with high and low FLFP persist with time in the host country, this indicates that culture is important. However, if all immigrant women, independently of FLFP, assimilate to the LFP of comparable natives, this indicates that factors in the host country might be more important. Blau et al. (2011) find that the number of hours spent on labor market work of female immigrants assimilates towards the levels of comparable female natives over time, but the gap between high and low-participation countries persists. These results suggest that the source country culture on gender roles has a persistent effect on immigrant women's labor supply behavior in the United States, and that the cultural impact neither decreases nor increases with time spent in the United States.

A challenge in the literature on culture and immigrant outcomes is to separate the impact of culture from other omitted source country and individual factors. To investigate if source country culture capture has omitted source country characteristics, the behavior of immigrant men can serve as a falsification test (Blau et al. 2011; Blau 2015). If the source country FLFP has the same impact on immigrant men and women, this indicates that the participation rate captures other omitted factors than culture, such as for example the productivity or work orientation in the source country. In the United States, immigrant men's labor supply is not affected by the FLFP, which strengthens the idea that the FLFP is capturing cultural differences in beliefs about the appropriate social role of women.

Furthermore, it is possible that individual factors, such as women's working experience and ability, is related to both women's working behavior in the host country and labor market conditions in the source country. Blau and Kahn (2015) conclude that immigrant women from high female participation countries might be more likely to have prior work experience. This could imply that the FLFP captures differences in women's working experience rather than culture. Blau and Kahn (2015) find that the relationship between FLFP and female immigrants' labor supply in the United States is robust to controlling for previous work experience in the source country. 
Moreover, immigrants might either be positively or negatively selected, such as having higher or lower income, ability or education than the average person in the source country who does not emigrate. In addition, the immigrants remaining in the host country might be different from those who eventually return to the source country. Lubotsky (2007) finds that migrants who stay in the United States tend to be positively selected, in the sense that they earn more than return migrants. For Sweden it has been shown that return migrants have higher educational attainment but lower earnings and labor market participation than stayers (Edin et al. 2000; Nekby 2006). Moreover, Edin et al. (2000) find that in Sweden migrants from OECD countries are more likely to return to their source countries than are non-OECD migrants. The authors show that the estimates of immigrants' earnings assimilation are positively biased due to selection in return migration for OECD-migrants, but not as biased among non-OECD migrants. Within each immigrant group it is the most successful who stay, but among the OECD migrants, this positive selection is more pronounced. If the selection patterns and/or return migration vary with the FLFP, the effect of culture might be misrepresented.

Previous studies have handled selection in migration by controlling for the distance to the source country and the source country's average emigration rate from the host country, and by studying married women who are often "tied movers" (the husband makes the migration decision) and arguably less selected (e.g., Blau et al. 2011; Blau and Kahn 2015). In a recent study, Finseraas and Kotsadam (2017) make use of a model with sibling-fixed effects to study the role of culture on gender roles for labor supply of second-generation immigrants in Norway. They find that the previous estimates of the correlation between culture and the labor supply of secondgeneration immigrants are likely biased upwards. This paper deals with selection in migration and omitted source country variables in a way that has not previously been adapted in this strand of literature. It uses a model with individual-fixed effects, ${ }^{3}$ implying that individual and source country factors that are constant over time are controlled for. This model enables us to study how the rate of assimilation is biased by the omission of unobservable time-constant factors, and whether this bias varies with FLFP. However, omitted time-varying factors can still influence the assimilation process and at the same time vary systematically with source country culture on gender roles, leading us to misrepresent the true effect of culture on labor market assimilation of immigrant women.

\section{Data and descriptive statistics}

\subsection{Data}

This paper uses longitudinal register data from the Longitudinal Integration Database for Health Insurance and Labor Market Studies (LISA) developed by Statistics

\footnotetext{
3 Eliasson (2014) shows that immigrant wage assimilation in Sweden is underestimated when neglecting to control for individual-fixed effects. Similar results are found in Beenstock et al. (2010) for Israel and Lubotsky (2007) for the United States, but Damas de Matos (2017) finds that individual-fixed effects do not affect the estimates of wage assimilation of immigrants in Portugal.
} 
Sweden. The data covers the period 1990 to 2007 and includes information on country of birth, year of immigration and other demographic characteristics and labor market outcomes, for everyone older than 16 years residing in Sweden. This means that everyone who lived in Sweden between 1990 and 2007 can be identified and tracked over time.

I study immigrants arriving in Sweden between 1980 and $1999 .{ }^{4}$ They are divided into two cohorts based on their year of arrival: (1) 1980 to 1989 (1980 cohort); and (2) 1990 to 1999 (1990 cohort). The reason for this division is that immigrants arriving in the 1990s were likely to be refugees, but those arriving in the 1980s usually came for economic reasons. ${ }^{5}$ Estimates of immigrants' earnings assimilation have been shown to be more affected by bias from selection in migration for economic migrants than for refugees (e.g., Edin et al. 2000). I have chosen not to have more cohorts spanning over fewer arrival years since this would result in some source countries lacking observations for all cohorts. Furthermore, the sample is restricted to source countries for which the place of birth is reported at the country level. As a result, analysis is performed on 25 source countries (see Table 2), divided into two cohorts. Using a variety of countries is important because of international contrasts in gender disparities. It is necessary to include countries with significant differences (such as Afghanistan) in addition to those with minor ones (such as the Nordic countries) to capture cultural differences. In addition, previous literature on the assimilation of immigrants in the Swedish labor market has concluded that immigrants from countries outside the OECD tend to have the largest gaps in employment and earnings relative to natives (e.g., Edin et al. 2000; Gustafsson and Zheng 2006; Hammarstedt 2003). Therefore, it is interesting to see whether similar assimilation patterns are found in relation to gender disparities.

I impose several restrictions on the sample. First, the sample is restricted to immigrants who arrived when they were older than 16 years, making it more likely for them to have been affected by gender norms in their source country. In addition, only individuals between the ages of 25 to 54 years are included, since these ages are likely to include people of working age both in Sweden and the source countries. Furthermore, to reduce bias from compositional changes because of return and onwards migration, I will impose the restriction that immigrants must remain in Sweden for at least 5 years to be included in the sample (e.g., Bratsberg et al. 2014; Sarvimäki 2011). ${ }^{6}$ Since data is not available before 1990, those arriving before 1985 will automatically be restricted to have remained in Sweden for a longer time period (6 to 10 years). For individuals with multiple immigration years only the first duration of stay in Sweden is considered. These restrictions give a total number of 1,790,827 unique individual-year observations for the 1980 cohort, and 1,973,190

\footnotetext{
$\overline{4}$ Because the data is available only after 1990 I have excluded earlier cohorts of migrants, since those migrants could not be studied during their first years of residence in Sweden.

5 For a detailed background on immigration to Sweden, see Lundh and Ohlsson (1999).

6 This is relevant for estimating the native-immigrant participation gap for the first year in Sweden. The individual-fixed-effects model will rely on within individual variation, which implies that the estimated rate of assimilation will be less biased by return and onwards migration.
} 
for the 1990 cohort (for sample sizes by immigrant group level see the Appendix, Table 5.) The composition of the cohorts changes as years since migration increases because of individuals leaving the sample due to death or emigration. In addition, in the 1980 cohort more individuals will enter the sample with the passage of time in Sweden. This is because the data starts in 1990, making it possible to include only those arriving in 1989 (51,549 individuals) to estimate the LFP at arrival. This will not affect the estimated rate of assimilation in the individual-fixed-effect model, but might bias the estimated native-immigrant participation gap for the first year in Sweden. The sample of immigrants will be compared to a sample of similar natives. The sample of natives is restricted to individuals between the ages of 25 and 54 years, and for computational reasons to a 10 percent representative sample. This yields a total number of 5,296,714 individual-year observations of natives.

I will analyze how the LFP of immigrant women changes as they spend time in Sweden. Individuals are defined as being in the labor force if they are employed or unemployed. Employment status is not directly observed in the data. I use a measure constructed by Statistics Sweden that approximates the ILO definition that a person who worked at least $1 \mathrm{~h}$ a week and received income is considered to be employed. ${ }^{7}$ A person is defined as unemployed if he or she has received unemployment benefits. As robustness, three other measures of labor supply are included. First, the probability of being employed is analyzed. Second, a measure that captures working time is constructed. Unfortunately I do not have access to information on individuals' working hours. However, I have access to data from the Wage and Salary Structure Data, which includes information on working time expressed as percentage of planned full-time (percentage of full-time) for all persons employed in the public sector and about 50 percent of all employees in the private sector. ${ }^{8}$ The percentage of full-time is sometimes adjusted for absence from work, but it cannot be observed when such corrections have been done. This implies that I observe the percentage of full-time with some measurement error. Furthermore, the Wage and Salary Structure Data is not representative for the full population, and since women are more likely to work in the public sector, they are oversampled. The sample provides information on the percentage of full-time for 3,084,392 out of the 6,464,772 individuals who are employed. Using information on percentage of full-time, I analyze two additional outcomes. The first is the probability to work at least 80 percent of full-time, which should be considered as a high degree of participation in labor market work. The shortcoming of this measure is that it does not capture differences at other margins of working time. Therefore, I include an analysis percent of full-time as a continuous variable.

The register data is appended with data on source country LFP for males and females, collected from the International Labor Organization's (ILO) database on labor statistics (LABORSTA). The LFP is defined as the share of employed or unemployed individuals out of the total population. When data is not provided by ILO, it has been collected elsewhere. (All exceptions are listed in Table 6 in the Appendix.) GDP per capita and educational attainment in the source countries have

\footnotetext{
The variable is referred to as Syssstat in the LISA database.

${ }^{8}$ Large firms are oversampled in this data. In Sweden, full-time employment corresponds to $40 \mathrm{~h}$ per week.
} 
been collected from the World Bank. ${ }^{9}$ Each cohort is assigned the value of the source country characteristics for the earliest arrival year of the years included in the cohort: 1980 for the 1980-1989 cohort, and 1990 for the 1990-1999 cohort. This implies that the source country variables are measured before migration took place. The advantage of this approach is that it allows the source country culture to change over time, whereas in studies measuring source country factors both before and after migration such changes might bias the results.

Although I try to make the measurements of source country variables comparable across countries, there are still some important differences in how they are measured. The outcomes are not always reported for people of different ages, implying that for some countries I will not compare participation gaps for people of the same age. In addition, outcomes will for some countries be measured for years that differ from the preferred years, because of lack of available data. Moreover, information on Russia is missing in the 1980s since it is not possible to identify Russians in the data during the 1980s. Table 6 in the Appendix gives an overview of the data sources and the collected data.

\subsection{Descriptive statistics}

Table 1 gives descriptive statistics for the sample, broken down by cohort and gender, with variable means calculated as an average for all individual-year observations. It appears that men have a somewhat higher labor force participation rate than women, but the largest differences are found when comparing immigrants with natives. Native women's LFP rate is about 89 percent, while about 73 percent of immigrant women arriving to Sweden in the 1980s, and 52 percent of immigrant women arriving to Sweden in the 1990s are part of the labor force. Among native men and immigrant men in the 1980 cohort, the rates are fairly similar to those of women. In contrast, among immigrant men arriving to Sweden in the 1990s the participation is nearly ten percentage points higher relative to that of women from the same immigrant cohort. The employment rates and working time follow a similar pattern as the LFP.

On average, immigrants in the 1980 cohort have been in Sweden about 12 years, close to double the amount of time that immigrants arriving in the 1990s have been in Sweden. Immigrants who came to Sweden in the 1980s were on average 27 years old, and those migrating in the 1990s were on average 30 years at arrival in Sweden (the median age of arrival for both groups is 31 ). It is noteworthy that individuals in the 1990 cohort are an average of 2 years younger than those who are native born or who arrived in Sweden in the 1980s. Apart from differences in age, the proportion of those who are not married, and the educational attainment are lower for immigrants than for natives.

Table 2 displays the female relative LFP (i.e., female LFP divided by male LFP) for all immigrant groups, calculated separately for each of the two cohorts. The rates in Sweden are displayed for similar years since migration for the two cohorts and the source country rates are measured before the first members of the cohort emigrated. It

\footnotetext{
${ }^{9}$ Geographical distance (as the crow flies) between the center of each source country's capital and Stockholm was measured using https://www.google.se/maps.
} 
Table 1 Descriptive statistics

\begin{tabular}{|c|c|c|c|c|c|c|}
\hline & \multicolumn{3}{|l|}{ Women } & \multicolumn{3}{|l|}{ Men } \\
\hline & $\begin{array}{l}\text { Cohort } \\
1980-1989\end{array}$ & $\begin{array}{l}\text { Cohort } \\
\text { 1990-1999 }\end{array}$ & Natives & $\begin{array}{l}\text { Cohort } \\
1980-1989\end{array}$ & $\begin{array}{l}\text { Cohort } \\
\text { 1990-1999 }\end{array}$ & Natives \\
\hline $\begin{array}{l}\text { Labor force } \\
\text { participation rate }\end{array}$ & 0.73 & 0.52 & 0.89 & 0.75 & 0.61 & 0.91 \\
\hline Employment rate & 0.60 & 0.43 & 0.83 & 0.59 & 0.50 & 0.86 \\
\hline $\begin{array}{l}\text { Percent of full- } \\
\text { time }^{\text {a }}\end{array}$ & 83.23 & 81.26 & 84.69 & 90.90 & 92.21 & 96.17 \\
\hline $\begin{array}{l}\text { Share working } \geq \\
80 \text { percent }^{\mathrm{a}}\end{array}$ & 0.67 & 0.66 & 0.67 & 0.85 & 0.87 & 0.94 \\
\hline Age & 39.75 & 36.82 & 39.53 & 39.67 & 37.44 & 39.47 \\
\hline $\begin{array}{l}\text { Years since } \\
\text { arrival }\end{array}$ & 12.47 & 6.80 & - & 11.99 & 6.69 & - \\
\hline Age at arrival & 27.28 & 30.02 & - & 27.68 & 30.74 & - \\
\hline Share married & 0.60 & 0.68 & 0.50 & 0.55 & 0.62 & 0.43 \\
\hline \multicolumn{7}{|l|}{ Education (share) } \\
\hline Primary school & 0.29 & 0.23 & 0.15 & 0.26 & 0.19 & 0.20 \\
\hline High school & 0.41 & 0.34 & 0.50 & 0.43 & 0.38 & 0.50 \\
\hline University & 0.27 & 0.29 & 0.34 & 0.25 & 0.30 & 0.29 \\
\hline $\begin{array}{l}\text { Number of } \\
\text { individuals }\end{array}$ & 60,646 & 88,040 & 222,217 & 67,052 & 84,428 & 233,189 \\
\hline $\begin{array}{l}\text { Number of } \\
\text { observations }\end{array}$ & 863,785 & $1,001,912$ & $2,588,388$ & 927,042 & 971,278 & $2,708,326$ \\
\hline
\end{tabular}

Sample is restricted to individuals in ages $25-54$, immigrants older than 16 years at arrival, and from any of the 25 countries listed in Table 2

${ }^{a}$ Information only available for a sub-sample of 3,084,392 individuals who are employed

appears that the migrants arriving in Sweden originate from countries with varying gender differences in labor market participation. The FLFP rates are generally lower than 1, implying that more males than females are participating in the labor force in the source countries. These rates have on average increased from about 0.54 in 1980 to around 0.62 in 1990. The FLFP rate is lowest for Afghanistan, Iran, Iraq, Lebanon, and Syria, where it is below 0.25. In the Nordic countries, China, and Thailand the relative participation rate it is around 0.9 .

It appears that after arrival in Sweden, immigrant men are still more likely than immigrant women to enter the labor force. Female immigrants who migrated in the 1980s had an LFP rate that was on average 87 percent of the rate for immigrant males 1 to 10 years after arrival. This can be compared to 98 percent among natives in the corresponding year. Women who immigrated to Sweden in the 1990s had an LFP rate that was on average 80 percent of the rate among males 1 to 10 years after arrival, while the corresponding number among natives was 97 percent.

It is worth noting that immigrant groups with the lowest FLFP, such as Afghanistan, Lebanon, and Syria also tend to have the lowest relative LFP in Sweden. Similarly, the Nordic countries and Thailand have the highest relative LFP both in 
Table 2 Female relative labor force participation rate for cohort-immigrant groups

\begin{tabular}{|c|c|c|c|c|}
\hline & \multicolumn{2}{|c|}{ Cohort 1980-1989 } & \multicolumn{2}{|c|}{ Cohort 1990-1999 } \\
\hline & $\begin{array}{l}\text { Source } \\
\text { country } \\
1980\end{array}$ & $\begin{array}{l}\text { Sweden } \\
1990\end{array}$ & $\begin{array}{l}\text { Source } \\
\text { country } \\
1990\end{array}$ & $\begin{array}{l}\text { Sweden } \\
2000\end{array}$ \\
\hline & (1) & (2) & (3) & (4) \\
\hline Afghanistan & 0.07 & 0.70 & 0.19 & 0.47 \\
\hline Chile & 0.36 & 0.85 & 0.44 & 0.84 \\
\hline China & 0.83 & 1.21 & 0.88 & 0.94 \\
\hline Denmark & 0.86 & 0.96 & 0.95 & 1.07 \\
\hline Ethiopia & 0.64 & 0.84 & 0.59 & 0.84 \\
\hline Finland & 0.88 & 1.11 & 0.94 & 1.12 \\
\hline $\begin{array}{l}\text { Former } \\
\text { Yugoslavia }\end{array}$ & 0.60 & 0.93 & 0.66 & 0.81 \\
\hline Germany & 0.57 & 0.98 & 0.71 & 0.89 \\
\hline Greece & 0.33 & 0.87 & 0.33 & 0.86 \\
\hline Hungary & 0.81 & 0.95 & 0.86 & 0.96 \\
\hline Iceland & 0.73 & 0.92 & 0.89 & 0.94 \\
\hline India & 0.37 & 0.88 & 0.41 & 0.72 \\
\hline Iran & 0.13 & 0.79 & 0.10 & 0.77 \\
\hline Iraq & 0.20 & 0.73 & 0.16 & 0.63 \\
\hline Lebanon & 0.15 & 0.47 & 0.25 & 0.50 \\
\hline Norway & 0.73 & 1.00 & 0.87 & 1.03 \\
\hline Poland & 0.83 & 0.94 & 0.84 & 0.92 \\
\hline Romania & 0.84 & 0.92 & 0.81 & 0.90 \\
\hline Russia & - & - & 0.96 & 0.78 \\
\hline Somalia & 0.42 & 0.70 & 0.46 & 0.40 \\
\hline Syria & 0.08 & 0.62 & 0.23 & 0.55 \\
\hline Thailand & 0.78 & 1.06 & 0.87 & 1.03 \\
\hline Turkey & 0.50 & 0.73 & 0.46 & 0.57 \\
\hline $\begin{array}{l}\text { United } \\
\text { Kingdom }\end{array}$ & 0.63 & 0.86 & 0.78 & 0.84 \\
\hline United States & 0.68 & 0.89 & 0.81 & 0.86 \\
\hline Average & 0.54 & 0.87 & 0.62 & 0.80 \\
\hline Natives & - & 0.98 & - & 0.97 \\
\hline
\end{tabular}

The table displays unadjusted female relative labor force participation rate, which is the share of females included in the labor force (employed or unemployed) divided by the share of males in the labor force. Source country rates are calculated for individuals aged 25-54; for data sources and exceptions see Appendix A, Table 6. Rates in Sweden are evaluated at 1-10 years since migration and the sample is restricted to immigrants in ages 25-54 years, older than 16 years at arrival in Sweden

the source countries and in Sweden. These descriptive patterns indicate that the source country culture, measured by the FLFP, might be important for immigrants' labor market behavior in Sweden. 


\section{Empirical specification}

To study how source country culture on gender roles influences the assimilation of immigrants in Sweden, I follow the empirical procedure developed by Borjas (1995). The specification follows the extension of this model presented in Bratsberg et al. (2014). ${ }^{10}$ The following equation is estimated separately by gender and cohort (1980 cohort and 1990 cohort):

$$
L_{i t}=\beta X_{i t}+\alpha_{1} I_{i}+\alpha_{2} A_{i t}+\alpha_{3} A_{i t} I_{i}+\alpha_{4} Y S M_{i t}+\alpha_{5} Z_{i} Y S M_{i t}+\rho H_{i} Y S M_{i t}+\gamma_{t}+\varepsilon_{i t}
$$

where $L_{i t}$ is an indicator for labor force participation of person $i$ in year $t . X$ is a vector of individual characteristics: indicators for having secondary or post-secondary education, an indicator for being married, the education and married indicators interacted with an indicator for being immigrant, and indicators for county of residence. ${ }^{11} I$ is an indicator for being an immigrant, $A$ is the individual's age in years, and $Y S M$ is the number of years since migration to Sweden. ${ }^{12} \mathrm{Z}$ is the source country female relative LFP rate and $H$ is a vector of other source country characteristics: GDP per capita, geographical distance to Sweden, and female as share of male enrollment rate in secondary school. Finally, $\gamma$ are year-fixed effects. The year-fixed effects are interacted with the immigrant indicator and the education indicators to allow potential business cycle effects to differ for immigrants and natives, and across individuals with different educational attainment. For further information on the variables included in the regressions, see Table 7 in the Appendix.

The coefficients estimated by Eq. [1] are used to predict assimilation profiles for women and men in the two cohorts separately. The assimilation profiles are estimated from 1 year after arrival in Sweden and until 28 years after arrival for immigrants arriving in 1980 to 1989 and 18 years after arrival for migrants coming in 1990 to 1999. The predicted LFP of immigrants as a deviation from natives' predicted LFP is evaluated at the median age of arrival (31 years), at average (the mean), low (the 25th percentile), and high (the 75th percentile) values of the FLFP, and at the means of all other variables.

Several assumptions need to be imposed to arrive at unbiased estimates of the effect of source country culture on the LFP assimilation of immigrants in Sweden. As noted by Fernández (2007), the average outcomes in the source countries are likely to depend on the institutional setting, economic environment, and on culture. However, immigrants do not bring with them the institutional and economic environment from their country of origin. As a result, the institutional setting and environment are the same for all immigrants in Sweden. Thus, if the FLFP has explanatory power for

\footnotetext{
${ }^{10}$ The empirical specification is closely related to the model outlined in Blau et al. (2011).

${ }^{11}$ Variables such as earnings and number of children are not included since they can be themselves affected by source country culture and endogenous to the assimilation process (Antecol 2000; Blau et al. 2011). However, the results are robust to including controls for number and age of children; see table A6 in the Appendix.

${ }^{12}$ I include a third-degree polynomial of YSM and a fourth-order polynomial of A. These are omitted in the equation to simplify notation. The results are robust to using a less flexible specification with only second-degree polynomials.
} 
labor market behavior in Sweden, this is likely to be because of the variation in FLFP that is due to source country culture. Still, I will not argue that I measure the causal effect of culture on assimilation, since the measure of culture on gender roles is a rather crude proxy and the estimates can be biased in a few ways.

To start with, other factors influencing both the FLFP and behavior in the Swedish labor market cannot be ruled out. For instance, educational differences between men and women in the source country probably affect the participation decisions in the source country and are at the same time important for preparedness for the Swedish labor market. By including source country control variables in Eq. [1], I control for part of such possible differences across source countries. Apart from controlling for gender differences in educational attainment in the source country, I also include GDP per capita, to rule out that the estimates capture differences in development, and geographical distance to Sweden, to avoid capturing differences in migration costs.

Furthermore, immigrants are not a representative sample of the population in their source country and, as appropriate in any study of immigration, such selection in migration needs to be taken into account (e.g., Borjas 1987). More specifically, the average immigrant from a country might be positively or negatively selected, such as having higher income, ability, or education than the average person in the source country who does not emigrate. This will affect the preparedness for the Swedish labor market and the work assimilation in Sweden. In addition, if return migration is selective, this can overstate or underestimate the degree of assimilation depending on whether the most or least able leave. If selection in migration varies systematically with the FLFP, the estimated effect of culture on the labor market assimilation will be biased.

Another factor worth remembering is that migrants might change their behavior after emigration because of shocks from language difficulties, discriminatory treatment, or absence of a community of people who share their cultural beliefs and gender norms. This implies that outcomes in Sweden are not representative for behavior in a situation where migration had not taken place and that culture could have a larger or smaller impact than what is indicated by the estimates.

To reduce the possible bias resulting from omitted individual and source country factors, a model including individual-fixed effects will be estimated. The following equation is estimated separately by gender and cohort (1980 and 1990):

$$
L_{i t}=\beta X_{i t}+\alpha_{2} A_{i t}+\alpha_{3} A_{i t} I_{i}+\alpha_{4} Y S M_{i t}+\alpha_{5} Z_{i} Y S M_{i t}+\rho H_{i} Y S M_{i t}+\gamma_{t}+\sigma_{i}+u_{m t}+\varepsilon_{i t}
$$

where all variables are defined as above and $\sigma$ denotes the individual fixed effects, and $u$ the yearly unemployment rate in the municipality of residence $(m)$. The advantage of the fixed-effect model is that $\sigma$ controls for all time-invariant individual characteristics. This implies that the assimilation profiles are identified using only within individual variation. ${ }^{13}$ In other words, the individual-fixed effects control for time-constant unobserved source country and individual characteristics, and implicitly for age at migration, cohort, and year of birth. Furthermore, relying on within individual variation implies that selection in return migration that is related to time-

13 See for instance Damas de Matos (2017), Eliasson (2014), Beenstock et al. (2010), and Lubotsky (2007) for immigrant wage assimilation models with individual-fixed effects. 
constant individual and source country factors will not bias the assimilations profiles. However, time-varying individual characteristics are not controlled for in the model and can still influence the assimilation process.

The fixed-effects model has the disadvantage of not being able to identify the LFP gap at arrival (i.e., include the immigrant indicator). The model also suffers from a collinearity problem, namely that year $=$ age + year of birth. The year-fixed effects are omitted from the model to identify the age coefficients of Eq. [2]. Period effects are instead considered by including interaction terms between the indicators for educational attainment and year of observation, and by controlling for the local unemployment rate $(u)$ (Barth et al. 2004). In the figures presented in Results section, I have imputed the immigrant deviation from the native LFP at the year of arrival, by computing the adjusted gap using the $\alpha_{1}$ s and the coefficients in $X$ that are interacted with the immigrant indicator estimated by Eq. [1]. The imputation affects the intercepts in the figures, but not the estimated rates of assimilation. To investigate how the omission of the year-fixed effects affects the difference between the results obtained from Eqs. [1] and [2], I estimate Eq. [1] excluding the year-fixed effects and including the local unemployment rate.

\section{Results}

\subsection{Baseline results}

The descriptive results presented in Table 2 show that the immigrant groups in Sweden with the lowest (highest) FLFP tended to have the lowest (highest) female labor force participation. However, this variation might be explained by differences in individual characteristics across immigrant groups. To ascertain whether this is true in the sample, I estimate Eqs. [1] and [2]. The full regression results are displayed in Table 8 in the Appendix; it appears that the FLFP rate is positively associated with immigrant women's LFP rate in Sweden for both the 1980 and 1990 cohorts, the exception being the individual-fixed effects estimates for the 1980 cohort. ${ }^{14}$ Among immigrant men, the FLFP is positively associated, but less so in comparison to women, with labor force participation in Sweden. However, when including individual-fixed effects there is a negative correlation for men.

The predicted differences in labor force participation between immigrant and native women are displayed in Table 3 and illustrated in Figs. 1 and 2. The predictions are calculated for three levels of the FLFP rate: at the mean, the 25th percentile, and the 75 th percentile. ${ }^{15}$ Columns 1 to 4 display the results from the model estimated with year-fixed effects and in columns 5 to 10 the year-fixed effects are excluded and individual-fixed effects are added.

\footnotetext{
14 This can be seen by the coefficient "Female relative LFP\# Years since migration" which shows the impact (in percentage points) on the LFP rate of women in that cohort (evaluated at the mean years since migration) of increasing the source country female relative LFP by one percent.

15 The mean is 0.56 in 1980 and 0.57 in 1990, the 25th percentile corresponds to a rate of 0.33 in 1980 and 0.25 in 1990, and the 75th percentile implies a rate of 0.83 in 1980 and 0.84 in 1990 .
} 


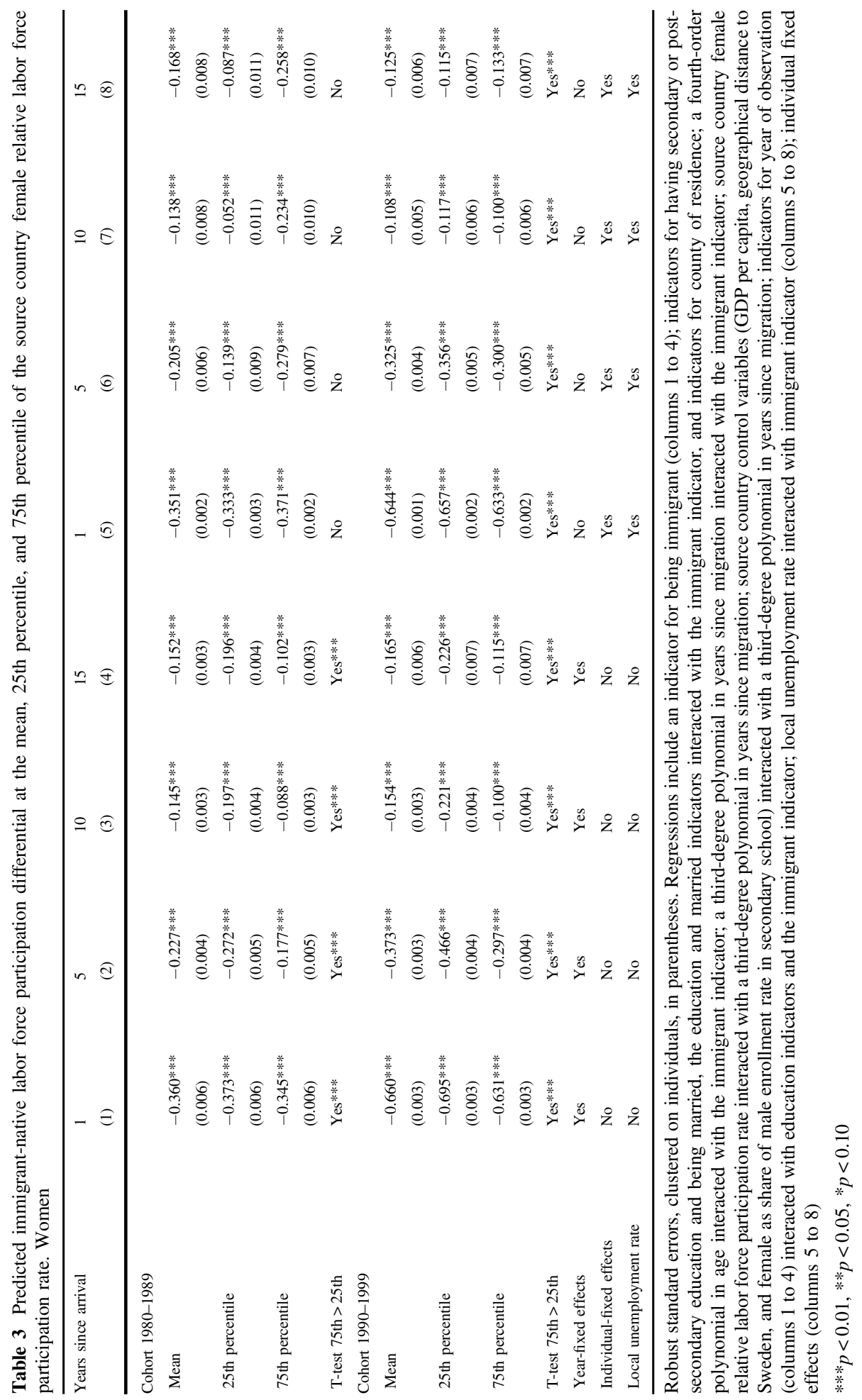




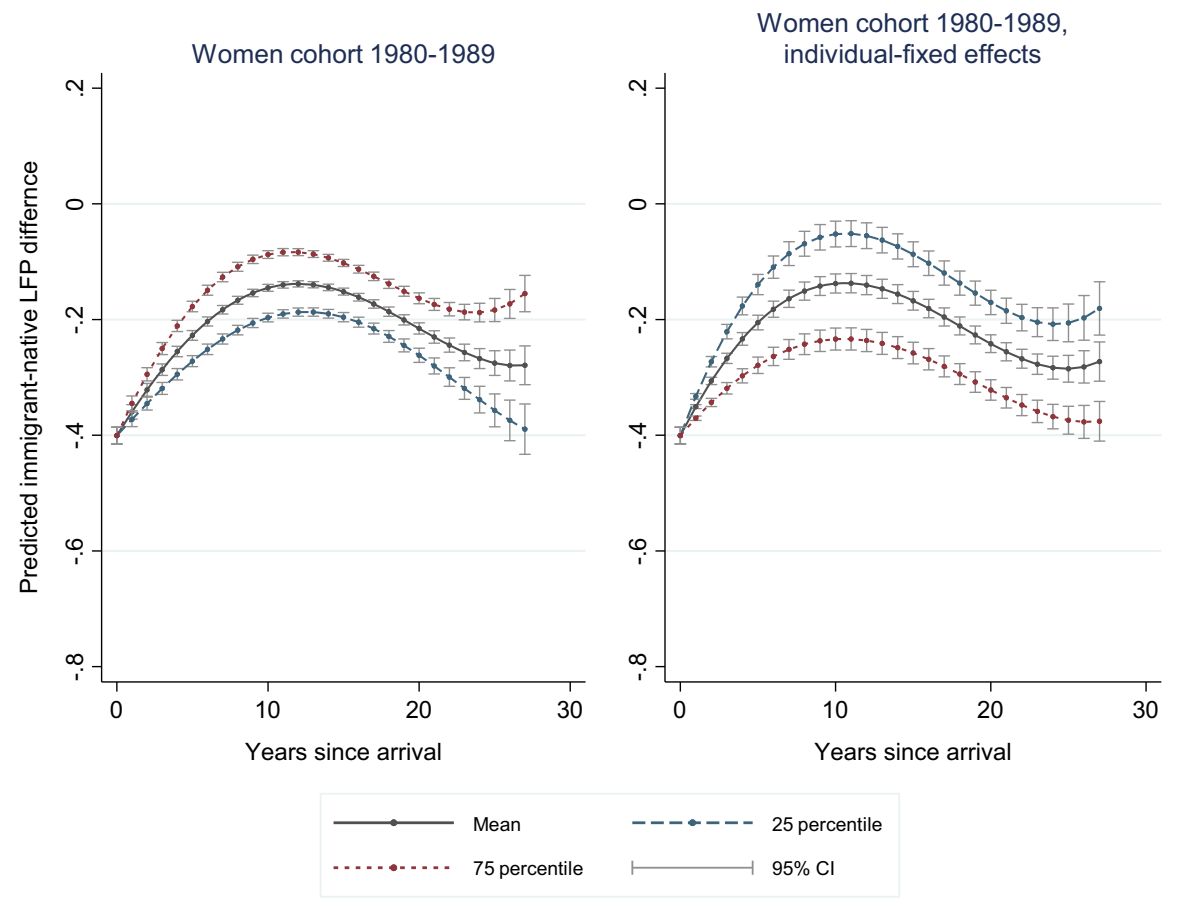

Fig. 1 Predicted assimilation profiles by source country female relative labor force participation rate. Women cohort 1980-1989

Immigrant women arriving to Sweden in the 1980s from a country with an average FLFP rate have a participation rate 1 year after arrival in Sweden that is 36 percentage points below that of native women. The immigrant-native gap is about one percentage point higher for women from countries with low female participation. Among women from countries with high FLFP, the gap in relation to natives is a bit smaller at about 35 percentage points. The difference between high and lowparticipation countries is about three percentage points 1 year after arrival, and the prediction for immigrants from countries with a FLFP at the 75th percentile is statistically significantly larger than the prediction for the 25th percentile. From columns 1 to 4 it emerges that the difference between high- and low-participation countries is positive, and the prediction at the 75 th percentile is statistically significantly larger than the prediction at the 25th percentile at the one percent level for all arrival years. The difference between high- and low-participation countries is, if anything, increasing with years since arrival, corresponding to between 4 and 13 percent of the cohort's mean LFP rate of 73 percent.

Turning now to the individual-fixed-effect estimates in columns 5 to 10, it appears that the difference between high- and low-participation countries is negative and increases with years of residence in Sweden. In Fig. 1, the discrepancy of the results with (to the left) and without (to the right) individual-fixed effects are even more clearly illustrated. It appears that the rate of assimilation is understated for the lowparticipation countries and exaggerated for the high-participation countries when 


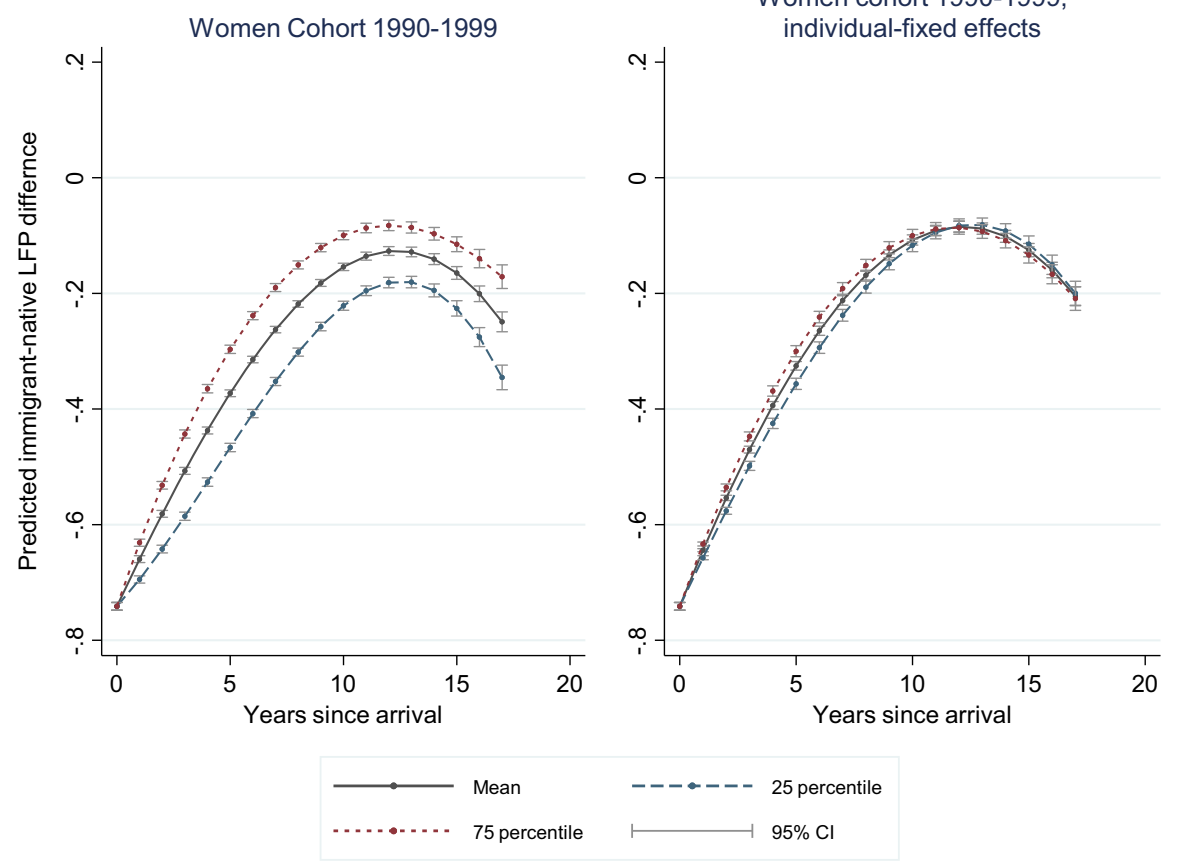

Fig. 2 Predicted assimilation profiles by source country female relative labor force participation rate. Women cohort 1990-1999

neglecting to control for individual-fixed effects. What explains these results for women arriving in the 1980s? Firstly, it is possible that among women from highparticipation countries, those least likely to work are also most likely to leave Sweden. This implies that the high rate of assimilation for the 75th percentile in the left graph in Fig. 1 is due to the negative selection of return migrants. In contrast, among migrants from low female participation countries, those returning are women who would have been likely to participate in labor market work had they stayed in Sweden. These results are in line with previous studies showing that return-migrants from OECD countries are negatively selected in terms of earnings capacity, and more so than non-OECD immigrants (Edin et al. 2000). ${ }^{16}$ Secondly, it is possible that other omitted time-constant factors, such as individuals' abilities and labor market preparedness, vary across immigrant groups and affect the assimilation profiles. Finally, the omission of the year-fixed effects could affect the slope of the assimilation curve. However, estimating the model without individual-fixed effects and including the local unemployment rate instead of the year-fixed effects to control for period effects does not have a major impact on the results (see Table 9 in the Appendix). Thus, selection in migration and/or omitted time-constant factors is likely to explain the discrepancy in the results.

\footnotetext{
16 All countries with low FLFP are non-OECD members (the exception being Greece), while among countries with high FLFP many are OECD members (exceptions being China, Thailand, Hungary, and Poland).
} 
The bottom of Table 3 displays the analogous predictions for women in the 1990 cohort. The results point in the same direction as for the 1980 cohort. However, the immigrant-native LFP gap is wider 1 year after arrival, and amounts to about 66 percentage points. In addition, the difference between high and low-participation countries is larger, starting at about six percentage points and with a peak at 17 percentage points 5 years after migration, which correspond to between 12 and 33 percent of the mean LFP rate of 52 percent. In contrast to the results for the 1980 cohort, the individual-fixed effects do not fully explain the LFP difference between the high and low-participation countries. In general, the difference between high and low-participation countries is positive when including individual-fixed effects (columns 5 to 8 ). However, the gap between high and low female participation countries is much smaller in comparison to the results in columns 1 to 4 , and amounts to about 3 to 12 percent of the cohort's mean participation rate of 52 percent. The predicted assimilation profiles for women in the 1990 cohort are displayed in Fig. 2. To the left in Fig. 2, the results without individual-fixed effects are displayed. It emerges that immigrant women do not reach parity with native women's labor force participation level and that high-participation countries, in comparison to low-participation countries, have higher LFP independently of length of residence in Sweden. When comparing these results to the fixed-effects predictions it emerges that the difference between high and low-participation countries is much smaller when time-constant individual factors are taken into account. ${ }^{17}$ Initially women from high-participation countries participate more in labor market work relative women from lowparticipation countries. However, the difference is eluded after about 15 years in Sweden, and neither women from high-participation countries nor those from lowparticipation countries reaches the LFP of native women.

How could the discrepancy of the results across cohorts be interpreted? To start with, it is important to keep in mind that the composition of source countries and the reasons for migrating change over time and this could affect assimilation in Sweden. During the 1990s, a larger share of the immigrants to Sweden were refugees, and refugee migration should be less likely to be selective than, for instance, migration for work or study. In addition, over time fewer immigrants in Sweden return to their source countries (Edin et al. 2000). More refugee migration and less return migration might explain why potential selection mechanisms bias the results more for the 1980 cohort than for the 1990 cohort.

To reinforce the validity of the results, I perform the same analysis on immigrant men. If the source country FLFP plays the same role for immigrant males' and females' labor market behavior, this indicates that there might be omitted factors that are correlated with the measure of culture. The results for men are presented in Table 4 and Figs. 3 and 4. The results in columns 1 to 4 show that immigrant men from high-participation countries have higher participation rates relative natives in comparison to men from low-participation countries. However, the magnitude of the difference between high and low-participation countries is considerable smaller than the corresponding estimates for women. Furthermore, when including individualfixed effects in columns 5 to 10 the difference between high and low-participation

17 The omission of the year-fixed effects is not a likely explanation for this result (see table A5 in the Appendix). 


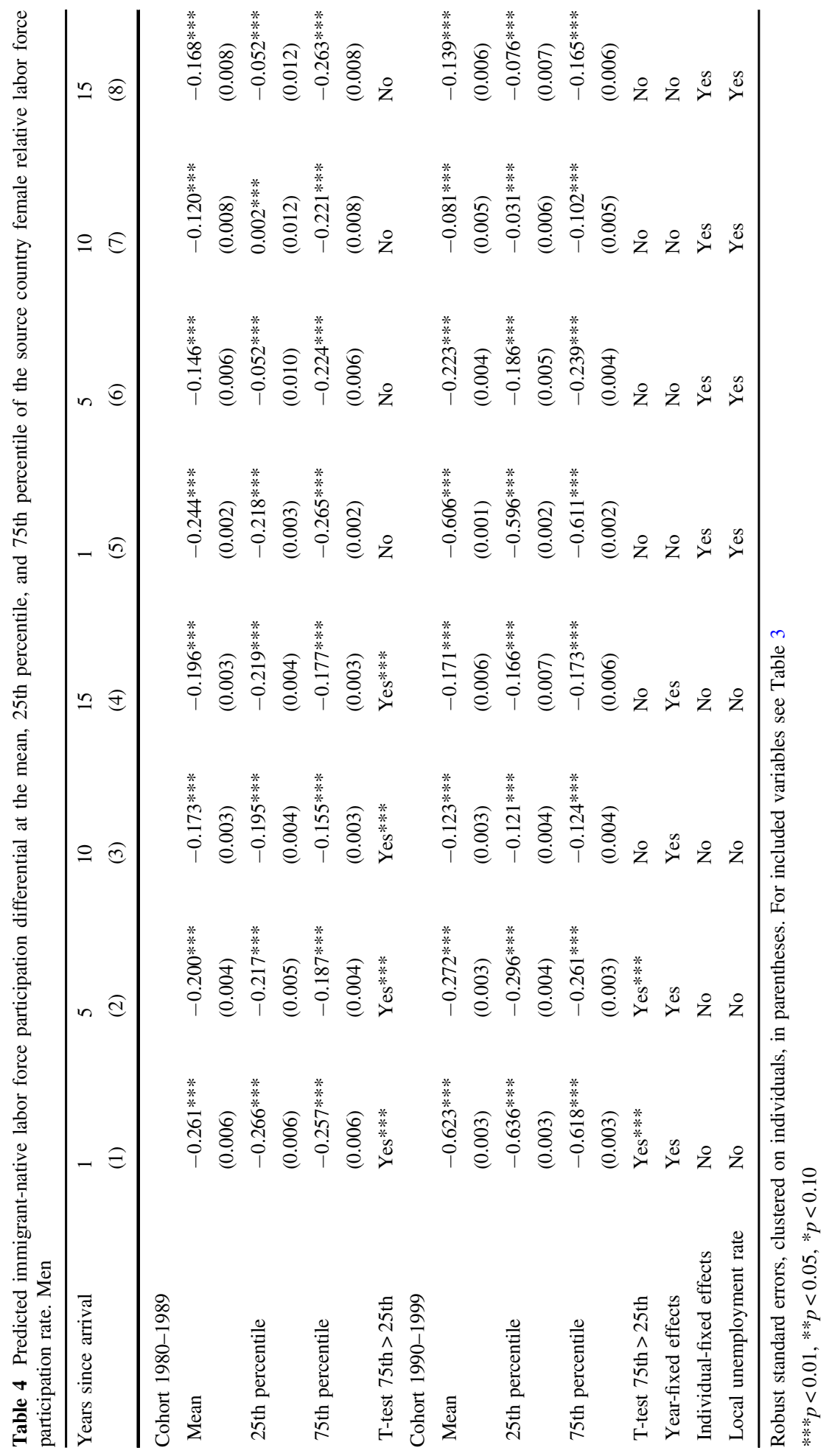




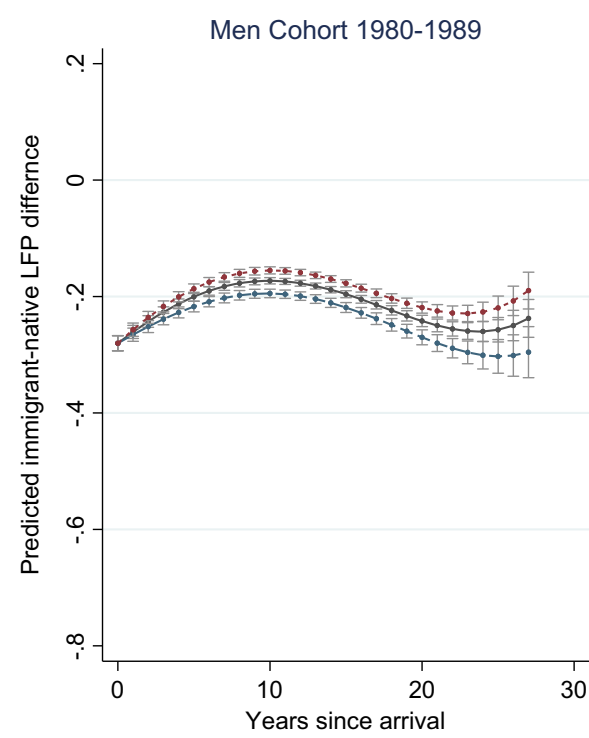

Men cohort 1980-1989,

individual-fixed effects
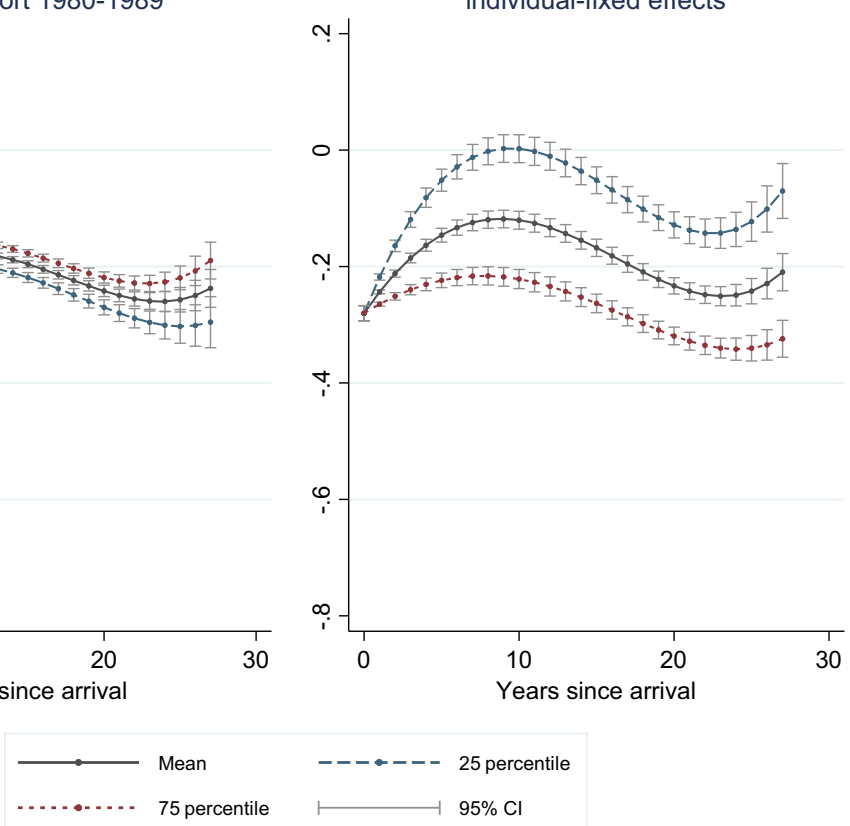

Fig. 3 Predicted assimilation profiles by source country female relative labor force participation rate. Men
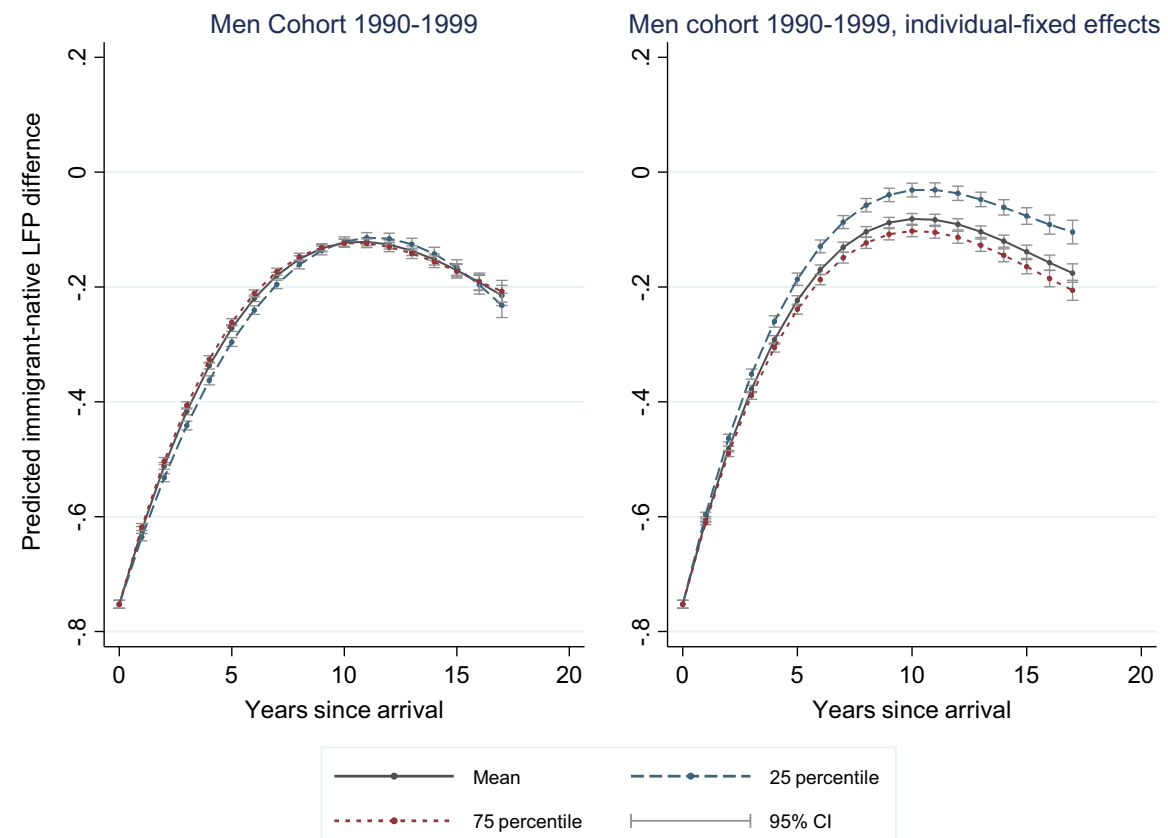

Fig. 4 Predicted assimilation profiles by source country female relative labor force participation rate. Men cohort 1990-1999 

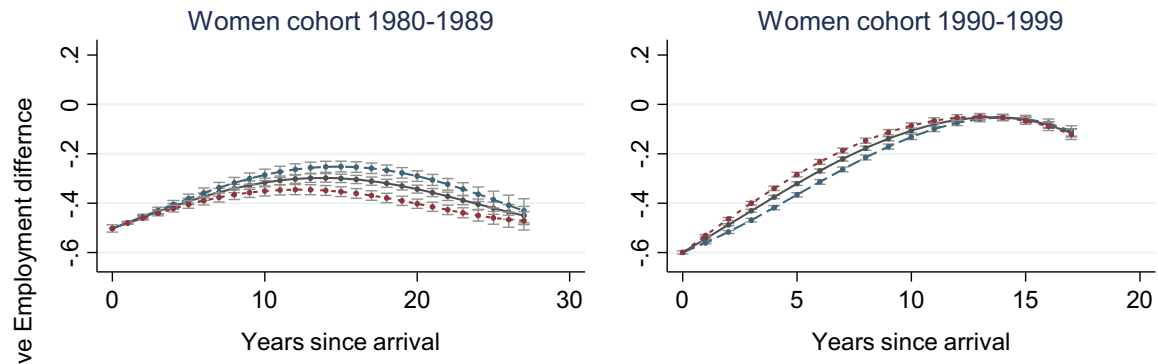

Men cohort 1980-1989

Men cohort 1990-1999
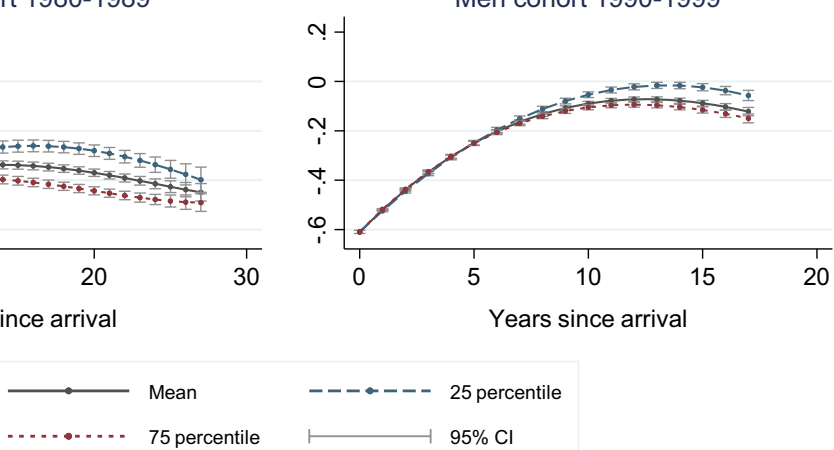

Fig. 5 Predicted employment assimilation profiles by source country female relative labor force participation rate. Note: Regressions include individual-fixed effects

countries is instead negative for both cohorts. Thus, source country female participation is not strongly correlated with immigrant men's labor market participation in Sweden. This strengthens the idea that the source country FLFP rate captures source country culture on gender roles rather than other omitted factors, such as work behavior, that affect men and women similarly.

\subsection{Additional results}

In the baseline results, the outcome considered is the decision to participate in labor market work. The aim is not to capture temporary transitions between employment and unemployment, but rather the decision to work or not. However, I conducted robustness tests ${ }^{18}$ to check if the results are similar for other outcomes. ${ }^{19}$ To start with, Eq. [2] is estimated with the outcome specified as the probability of being employed. The predicted immigrant-native employment rate differences among women and men are shown in Fig. 5. Overall, the results for employment are consistent with the results for labor force participation. For immigrant women arriving in the 1990s, from high-participation countries, their employment rate is about three percentage points higher than for women from low-participation countries 1 year

\footnotetext{
18 All regression results from the robustness checks are available from the author upon request.

19 Blau and Kahn (2015) find similar impacts of source country culture on hours of work, employment, and labor force participation.
} 

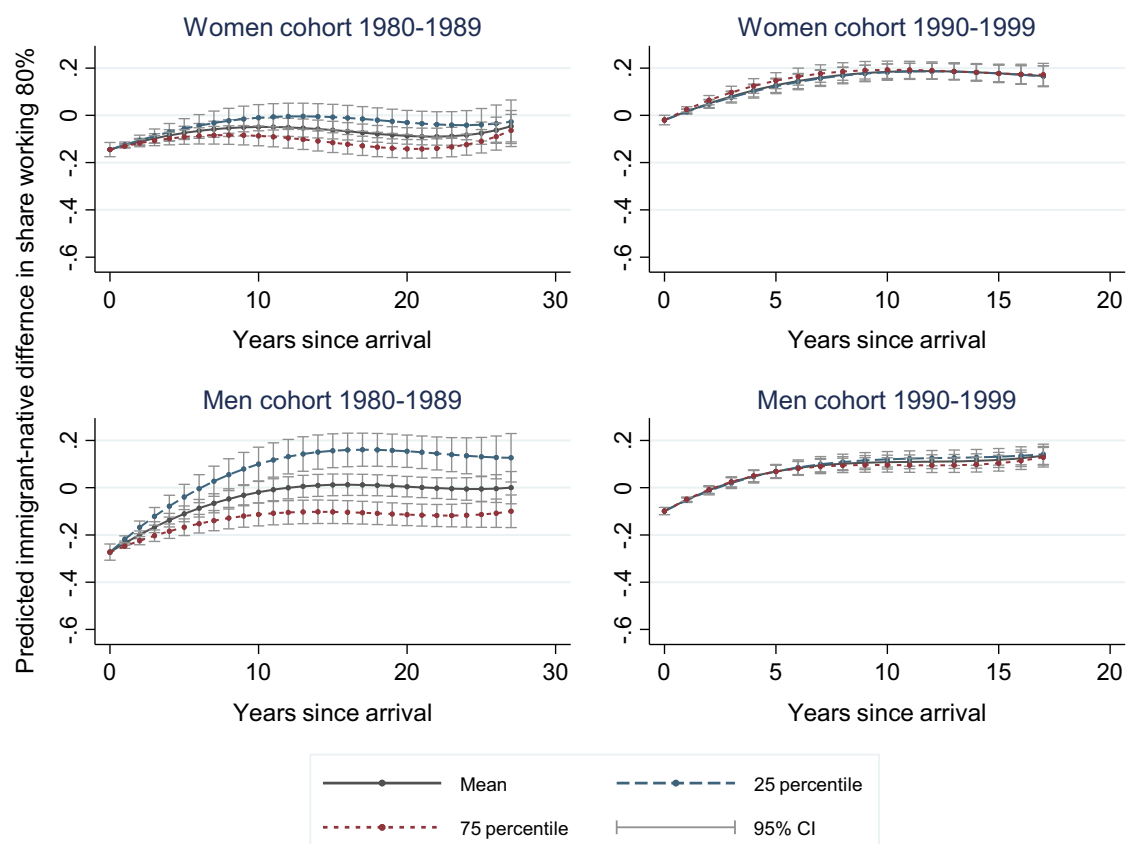

Fig. 6 Predicted assimilation profiles by source country female relative labor force participation rate. Outcome is probability of working at least 80 percent of full-time. Note: Regressions include individualfixed effects

after arrival in Sweden. After 5 years in the Sweden this difference amounts to around eight percentage points, and 15 years after migration there is no longer any difference between high and low-participation countries. These results can be contrasted to the findings for the United States, where difference in employment rates between high- and low-participation countries is around six percentage points, independently of length of residence in the United States (e.g., Blau et al. 2011).

In previous studies, immigrant women's labor supply assimilation has been investigated with respect to the number of hours worked in the host country (Blau et al. 2011; Blau 2015; Blau and Kahn 2015). This is also relevant for Sweden, especially since many women in Sweden do not work full-time (Statistics Sweden 2016). Immigrant women from Africa and the Middle East work fewer hours than natives (Andersson 2011). Therefore I analyze two additional outcomes. The first is the probability of working at least 80 percent of full-time hours, which should be considered as a high degree of participation in labor market work. Second, I specify a model with percentage of full-time as a continuous variable.

The results from the estimations of Eq. [2] with the outcome specified as (i) the probability to work at least 80 percent of full-time, and (ii) percent of full-time are presented in Figs. 6 and 7. In general, the results point in the same direction as the baseline results for LFP. However, the differences between native and immigrant women seem to be smaller when labor supply is considered at the intensive margin. Similarly, the difference in working time between women from high- and lowparticipation countries is smaller than the disparity in participation rates. For 

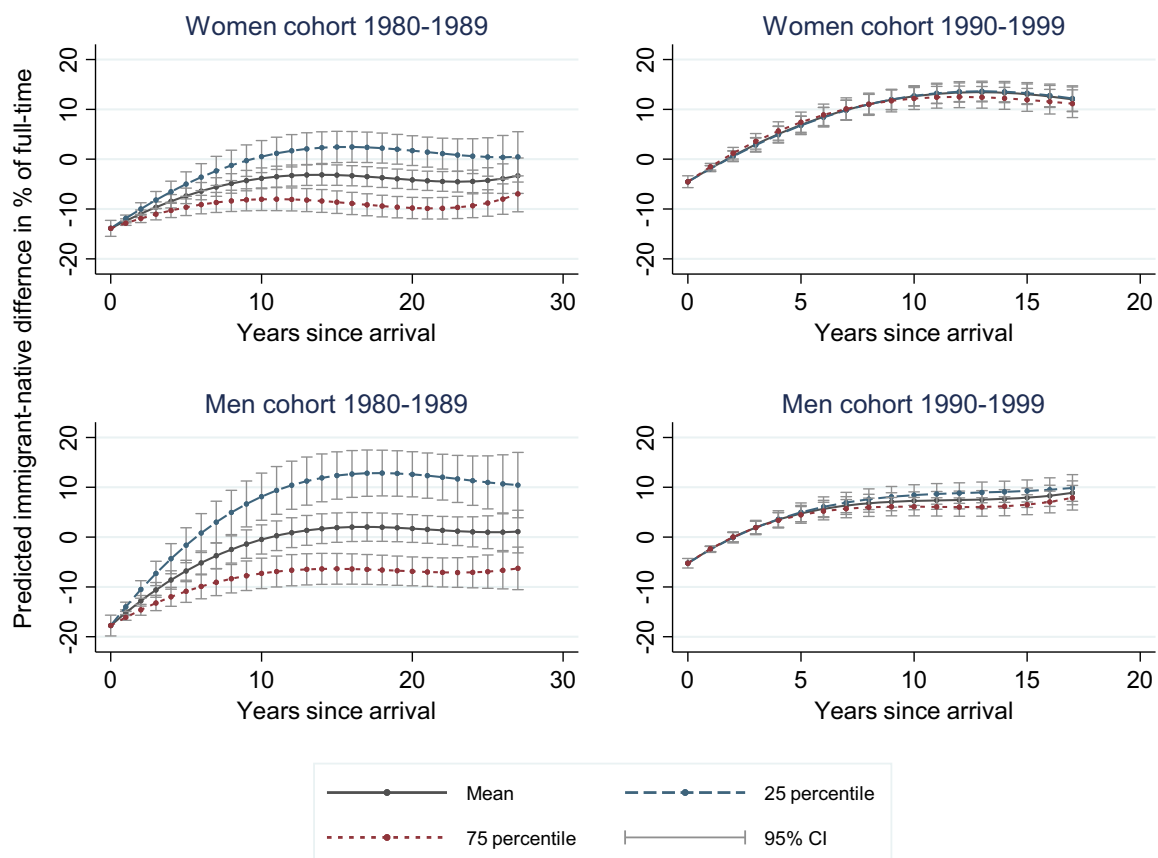

Fig. 7 Predicted assimilation profiles by source country female relative labor force participation rate. Outcome is percent of full-time. Note: Regressions include individual-fixed effects

immigrant women arriving in the 1990s the gap between high- and low-participation countries in percent of full-time is largest 4 years after arrival in Sweden. Among women that migrated from a high-participation country the percent of full-time is about one percentage point higher than for immigrant women from low-participation countries 3 years after arrival. This result can be translated into differences in hours by using the annual working time of $1980 \mathrm{~h}^{20}$ Native women work on average 84.7 percent of full-time, which corresponds to about $1677 \mathrm{~h}$ a year. Immigrant women arriving in the 1990s from low-participation countries work about $82 \mathrm{~h}$ more than native women. Women from high-participation countries work around $94 \mathrm{~h}$ more, a difference of about $12 \mathrm{~h}$ in annual working time. This result can be contrasted to the findings for the United States, where hours given to employment are 43 to $66 \mathrm{~h}$ higher for immigrant women from high-participation countries in comparison to women from low-participation countries (e.g., Blau et al. 2011). Finally, the finding that the source country FLFP primarily influences labor supply on the extensive margin and not as much the intensive margin is consistent with previous findings for the United States (e.g., Blau et al. 2011).

I performed two robustness tests where the sample is restricted in different ways. First, I estimated the model separately for women who are married or cohabitate with a man and have children and for single women. ${ }^{21}$ The results are presented in Figs. 8

${ }^{20}$ The annual working time in Sweden is $165 \mathrm{~h}$ a month, which corresponds to $1980 \mathrm{~h}$ a year.

${ }^{21}$ In the data it is not possible to identify cohabitating couples without children. 
and 9 in the Appendix. In general, the results point in the same direction as the results for the full sample. In line with previous research (e.g., Blau et al. 2011) there is no evidence that the LFP difference between married/cohabitating women from high and low-participation countries is larger than the corresponding difference among single women. However, single women, in contrast to married/cohabitating women, appear to reach the LFP rate of native women after 5 to 10 years of residence in Sweden. In addition, I test if the results are robust to excluding immigrants from former Yugoslavian countries, who compose a large fraction of the sample especially in the 1990 cohort. The results are presented in Figs. 10 and 11 in the Appendix and are very similar to the baseline results.

\section{Conclusions}

The fact that men tend to participate in labor market work to a larger extent than women has attracted the attention of researchers, policy makers, and media. The literature has offered numerous explanations, such as discrimination, institutional setting, preferences, and social norms as reasons for the persistence of gender gaps in labor market outcomes. This paper investigates the role of one of these explanations - culture on gender roles-which is the totality of differences in preferences and beliefs about gender roles across groups with different cultural backgrounds. It investigates whether the source country culture on gender roles, measured by the female relative labor force participation rate, is an important factor in the assimilation of immigrant women's labor market participation to that of comparable native women in Sweden.

Our results show that immigrant women arriving in Sweden in the 1980s have about 36 percentage points lower LFP rate than their native counterparts, and that the gap is reduced by about half after 15 years of residence in Sweden. Furthermore, immigrant women from countries with a high FLFP rate (at the 75th percentile of the distribution) have between three and ten percentage points higher participation rates than do women from countries with a high FLFP rate (at the 25th percentile of the distribution). However, these results seem to be driven by differences in individual characteristics between immigrants from low- and high-participation countries. The estimates obtained when controlling for individual-fixed effects indicate that immigrant women from low-participation countries engage in labor market work to a higher degree than immigrant women from high-participation countries. A reasonable explanation of this result is that selection in return migration and/or other unobservable time-constant factors, such as individuals' abilities and labor market preparedness, is correlated both with immigrants' FLFP and labor market assimilation.

Moreover, among immigrant women in the 1990 cohort, the native-immigrant LFP rate gap at arrival amounts to about 66 percentage points. Women from highparticipation countries have between 7 and 17 percentage points higher participation rate than do women from low-participation countries. The role of FLFP is reduced substantially when controlling for individual-fixed effects, but for the first 15 years of residence in Sweden women from high-participation countries work more than women from low-participation countries. However, neither women from high- 
participation countries nor those from low-participation countries reach the participation level of native women.

Furthermore, to strengthen the validity of the results, the same analysis is conducted on immigrant men. If the source country female participation plays the same role for immigrant males' and females' labor market behavior this indicates that factors that are correlated with the measure of source country culture might have been omitted. In general, the FLFP is not strongly correlated with immigrant men's labor market participation in Sweden. This strengthens the belief that the FLFP captures source country culture on gender roles rather than other omitted factors, such as work behavior, that affect men and women similarly.

In previous literature, source country culture on gender roles has been found to be important for immigrant women's labor supply in their new host country. Blau et al. (2011) find that upon arrival, immigrant women in the United States work fewer hours and participate in labor market work less than native women. Over time, women from high-participation countries catch up with natives, whereas women from countries with low FLFP rates do not. In the baseline model I find similar results, but when controlling for individual-fixed effects the FLFP is not explaining the rate of assimilation. In general, immigrant women from low-participation countries increase their participation and working time more than do women from high-participation countries as time in Sweden increases. In other words, the source country culture on gender roles could have a less persistent impact on labor supply in Sweden than in the United States. From a policy perspective, the results presented in this paper reveal a need for policies addressing other factors than immigrant women's views on gender roles in order to bring immigrant women's participation to the same level of native women's.

I conclude that source country culture on gender roles appears to be one of many possible explanations for the low labor force participation rate of some immigrant women in Sweden. However, the influence of culture on immigrant women's labor market behavior appears to decrease with their length of time in their new host country, Sweden. With the Swedish institutional setting in mind, it seems likely that the number of institutions encouraging female labor force participation, such as child care and parental leave systems, helps to bring down cultural barriers. In particular since the differences in LFP between women from low- and high-participation countries decreases over time in Sweden and not in the United States, a country with less generous public child-care and parental leave opportunities than those available in Sweden. However, it is also possible that immigrant women's preferences and beliefs about gender roles change and become more in line with native Swedish women's with passage of time since migration. To conclude with certainty whether or not Sweden's institutional setting is a driving force for cultural assimilation, more research on other countries with different institutions and at other levels of economic development is needed. Finally, it would be fruitful for future research to focus more on exploring these interactions between culture on gender roles and institutions and on how they evolve over time, in order to make more precise policy recommendations aimed at increasing gender equality.

Acknowledgements I wish to thank two anonymous referees, Lina Aldén, Abdul Aziz Ali, Mahmood Arai, Dominique Anxo, Karin Edmark, Mats Hammarstedt and Per Skedinger, as well as 
seminar participants at Linnaeus University and The Institute for Analytical Sociology at Linköping University, and participants at the 2nd SWEGPEC Workshop in Jönköping for useful comments on an earlier version of this paper.

\section{Compliance with ethical standards}

Conflict of interest The author declares that she has no conflict of interests.

\section{Appendix}

Figures $8-11$ and Tables 5-10

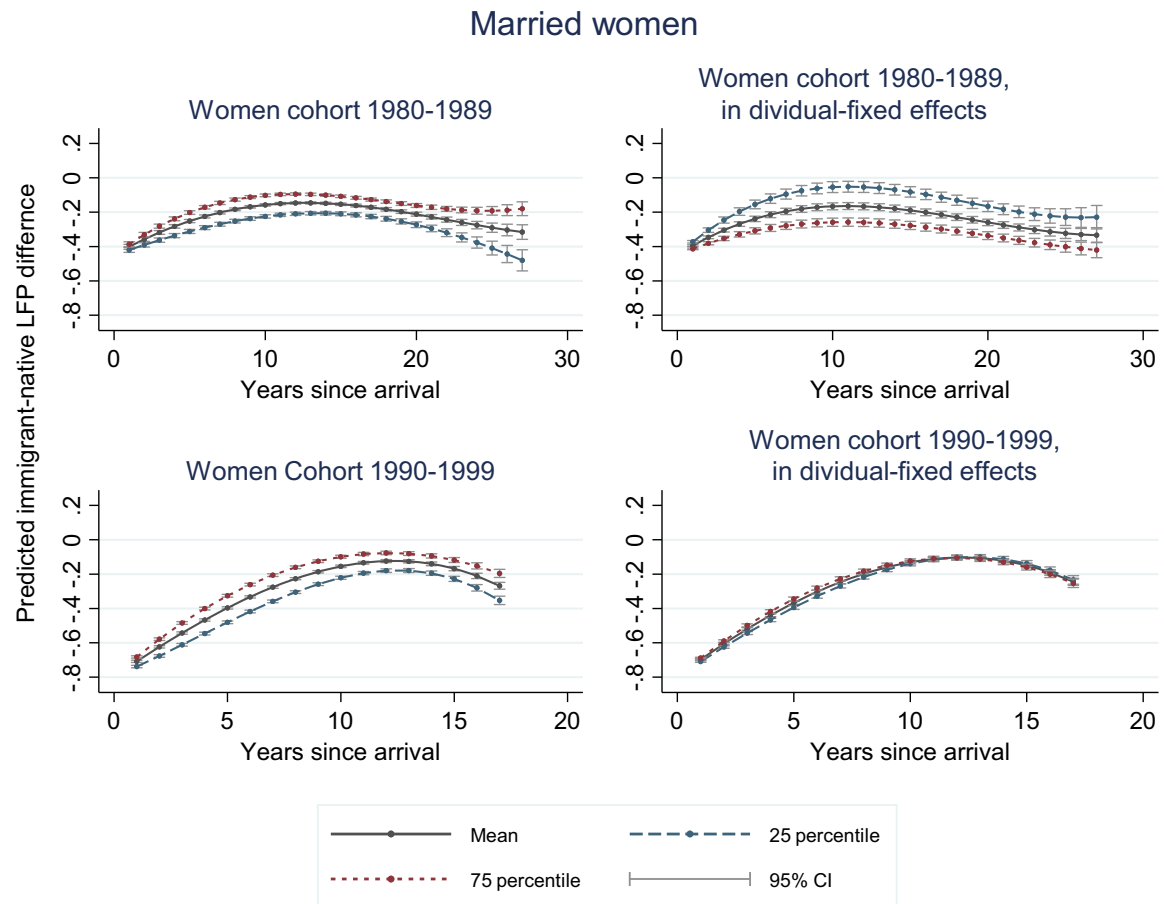

Fig. 8 Predicted assimilation profiles by source country female relative labor force participation rate. Sample restricted to married/cohabitating women 


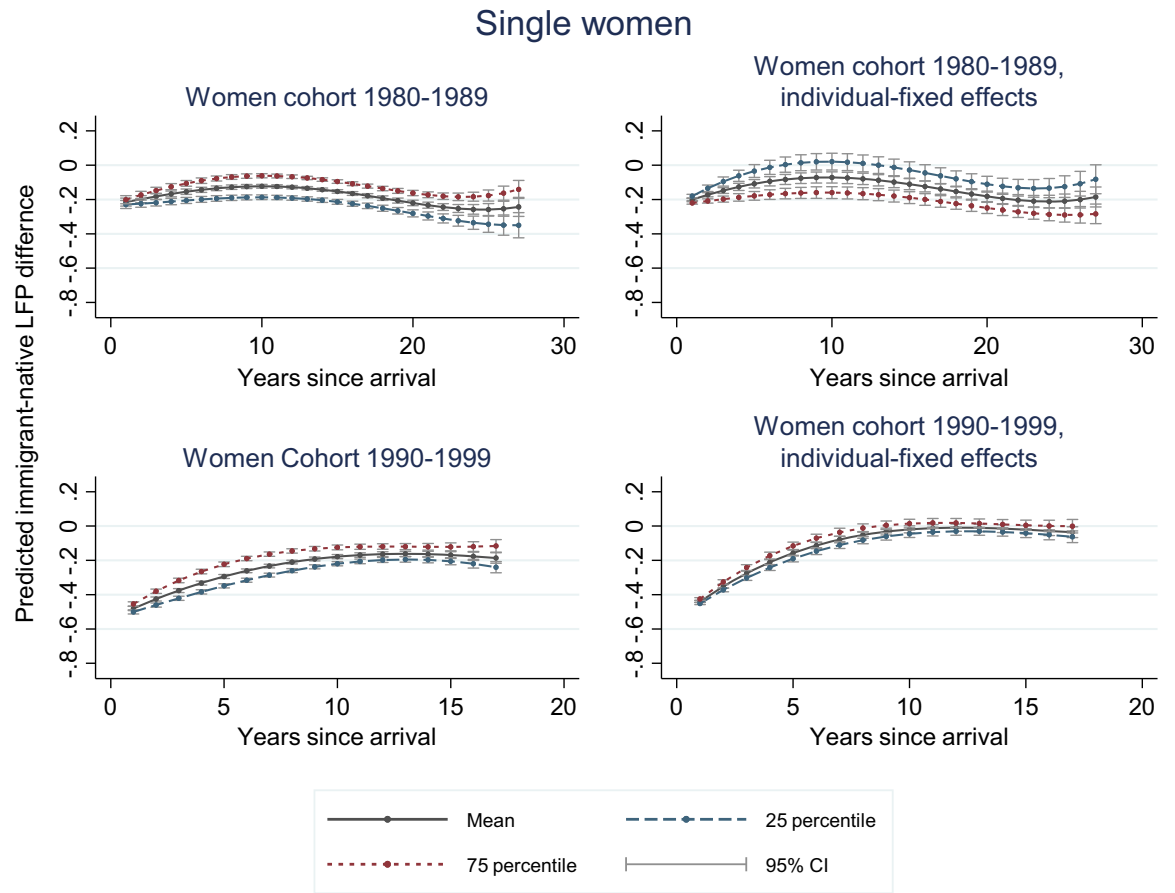

Fig. 9 Predicted assimilation profiles by source country female relative labor force participation rate. Sample restricted to single women 


\section{Excluding Yugoslavia}

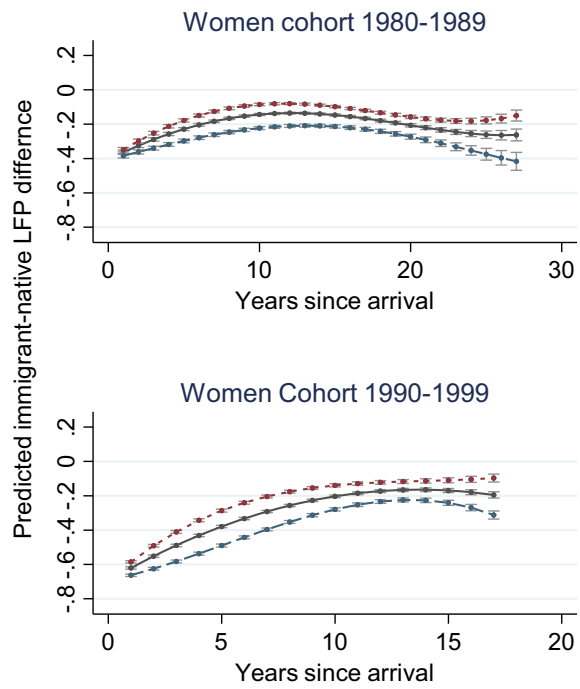

Women cohort 1980-1989,

in dividual-fixed effects

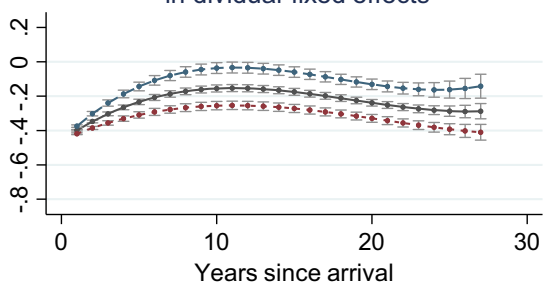

Women cohort 1990-1999,

in dividual-fixed effects
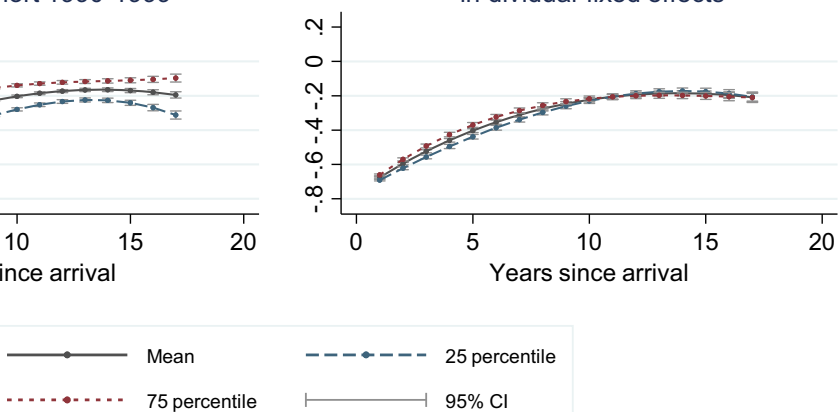

Fig. 10 Predicted assimilation profiles by source country female relative labor force participation rate. Women, excluding migrants from former Yugoslavia

\section{Excluding Yugoslavia}

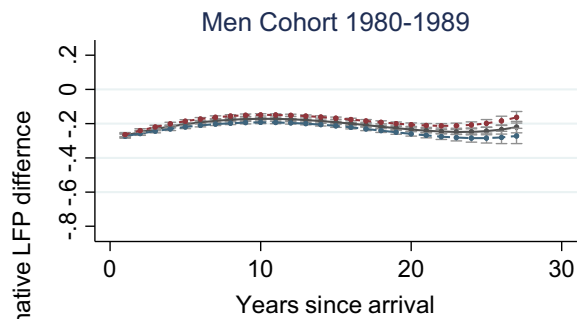

Men cohort 1980-1989, individual-fixed effects

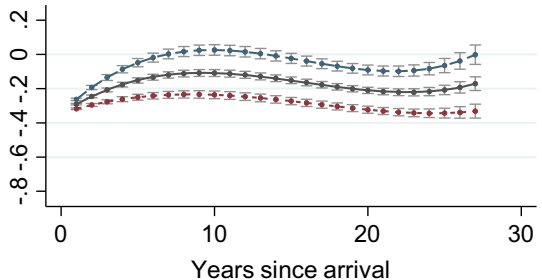

Men cohort 1990-1999, individual-fixed effects
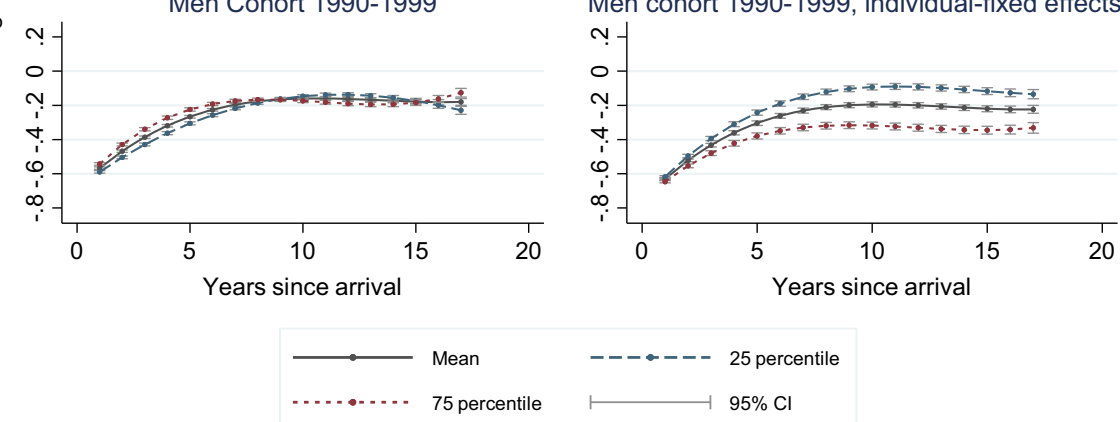

$95 \% \mathrm{Cl}$

Fig. 11 Predicted assimilation profiles by source country female relative labor force participation rate. Men, excluding migrants from former Yugoslavia 
Table 5 Number of yearly observations by cohort-immigrant group. Average over years 1990-2007

\begin{tabular}{|c|c|c|}
\hline & Cohort 1980-1989 & Cohort 1990-1999 \\
\hline Afghanistan & 236 & 910 \\
\hline Chile & 8525 & 1847 \\
\hline China & 1055 & 1982 \\
\hline Denmark & 2775 & 2123 \\
\hline Ethiopia & 2968 & 2420 \\
\hline Finland & 12,649 & 5285 \\
\hline Former Yugoslavia & 4434 & 33,730 \\
\hline Germany & 1821 & 2104 \\
\hline Greece & 1524 & 801 \\
\hline Hungary & 1889 & 708 \\
\hline Iceland & 693 & 606 \\
\hline India & 968 & 781 \\
\hline Iran & 18,633 & 8322 \\
\hline Iraq & 4718 & 13,490 \\
\hline Lebanon & 4804 & 4337 \\
\hline Norway & 4752 & 3207 \\
\hline Poland & 9100 & 4361 \\
\hline Romania & 2901 & 2069 \\
\hline Russia & - & 1829 \\
\hline Somalia & 406 & 4357 \\
\hline Syria & 2931 & 3611 \\
\hline Thailand & 1448 & 2394 \\
\hline Turkey & 6189 & 4090 \\
\hline United Kingdom & 2346 & 2298 \\
\hline United States & 1725 & 1960 \\
\hline
\end{tabular}

Table 6 Source country data

\begin{tabular}{llll}
\hline & Year & Age restriction & Source \\
\hline Afghanistan & 1990 & $15-64$ & World Bank \\
Chile & 1980,1990 & $25-54$ & ILO \\
China & 1982,1990 & $15-64$ & World Bank \\
Denmark & $1979 / 1981,1990$ & $25-54$ & ILO \\
Ethiopia & 1980,1990 & $25-54$ and 15-64 & ILO and World Bank \\
Finland & 1980,1990 & $25-54$ & ILO \\
Former Yugoslavia & 1981,1990 & $25-49$ & ILO \\
Germany & 1980,1990 & $25-54$ & ILO \\
Greece & 1981,1992 & $25-54$ and 25-64 & ILO \\
Hungary & 1980,1990 & $25-54$ & ILO \\
Iceland & $1979 / 1981,1990$ & $25-54$ and 15-64 & ILO and World Bank \\
India & 1981,1991 & $15-64$ and total population & World Bank and Acharya (1996) \\
Iran & $1976 / 1986,1991$ & $25-54$ & ILO \\
& & & \\
\hline
\end{tabular}


Table 6 continued

\begin{tabular}{llll}
\hline & Year & Age restriction & Source \\
\hline Iraq & 1977,1990 & $25-54$ and 15-64 & ILO and World Bank \\
Lebanon & 1975,1990 & $25-54$ or 15-64 & ILO and World Bank \\
Norway & 1980,1990 & $25-54$ & ILO \\
Poland & $1978,1988 / 1995$ & $25-54$ & ILO \\
Romania & 1977,1992 & $25-54$ & ILO \\
Russia & $1989 / 1992$ & $25-54$ & ILO \\
Somalia & 1990 & $25-54$ and 15-64 & ILO and World Bank \\
Syria & 1979,1990 & $25-54$ and 15-64 & ILO and World Bank \\
Thailand & 1980,1990 & $25-54$ and 25-59 & ILO \\
Turkey & 1980,1990 & $25-54$ & ILO \\
United Kingdom & 1981,1990 & $25-54$ & ILO \\
United States & 1980,1990 & $25-54$ & ILO \\
\hline
\end{tabular}

Table 7 Description of variables included in regressions

\begin{tabular}{|c|c|}
\hline Variable & Description \\
\hline \multicolumn{2}{|l|}{ Dependent variable } \\
\hline Labor force participation & 1 if unemployed or employed, 0 otherwise \\
\hline Employed & 1 if employed, 0 otherwise \\
\hline $\begin{array}{l}\text { Probability to work at least } 80 \text { percent } \\
\text { of full-time }\end{array}$ & 1 if work $\geq 80$ percent of full-time, 0 otherwise \\
\hline Percent of full-time & Continuous \\
\hline \multicolumn{2}{|l|}{ Independent variables } \\
\hline Immigrant & 1 if foreign born, 0 otherwise \\
\hline Age & Continuous \\
\hline $\mathrm{Age}^{2}$ & Continuous \\
\hline $\mathrm{Age}^{3}$ & Continuous \\
\hline $\mathrm{Age}^{4}$ & Continuous \\
\hline Immigrant\# Age & Age interacted with the indicator for immigrant \\
\hline Immigrant\# Age ${ }^{2}$ & $\mathrm{Age}^{2}$ interacted with the indicator for immigrant \\
\hline Immigrant\# $\mathrm{Age}^{3}$ & $\mathrm{Age}^{3}$ interacted with the indicator for immigrant \\
\hline Immigrant\# Age $^{4}$ & $\mathrm{Age}^{4}$ interacted with the indicator for immigrant \\
\hline Years since migration & Continuous \\
\hline Years since migration $^{2}$ & Continuous \\
\hline Years since migration ${ }^{3}$ & Continuous \\
\hline Years since migration\# FLFP & $\begin{array}{l}\text { Both continuous. FLFP is the source country female relative } \\
\text { LFP, i.e. female LFP divided by male LFP. }\end{array}$ \\
\hline Years since migration ${ }^{2} \#$ FLFP & Both continuous. \\
\hline Years since migration ${ }^{3} \#$ FLFP & Both continuous. \\
\hline Years since migration \# GDP & $\begin{array}{l}\text { Both continuous. GDP refers to the source country GDP per } \\
\text { capita. }\end{array}$ \\
\hline Years since migration ${ }^{2} \#$ GDP & Both continuous. \\
\hline
\end{tabular}


Table 7 continued

\begin{tabular}{|c|c|}
\hline Variable & Description \\
\hline Years since migration ${ }^{3} \#$ GDP & Both continuous. \\
\hline Years since migration\# Distance & $\begin{array}{l}\text { Both continuous. Distance is the geographical distance from } \\
\text { source country's capital to Stockholm in Sweden. }\end{array}$ \\
\hline Years since migration ${ }^{2} \#$ Distance & Both continuous. \\
\hline Years since migration ${ }^{3} \#$ Distance & Both continuous. \\
\hline $\begin{array}{l}\text { Years since migration\# Female } \\
\text { relative schooling }\end{array}$ & $\begin{array}{l}\text { Both continuous. Female relative schooling is the female } \\
\text { enrollment rate in secondary schooling divided by the male } \\
\text { enrollment rate in secondary schooling. }\end{array}$ \\
\hline $\begin{array}{l}\text { Years since migration }{ }^{2} \# \text { Female } \\
\text { relative schooling }\end{array}$ & Both continuous. \\
\hline $\begin{array}{l}\text { Years since migration }{ }^{3} \# \text { Female } \\
\text { relative schooling }\end{array}$ & Both continuous. \\
\hline Year & $\begin{array}{l}\text { Year of observation. Indicators with the first year of } \\
\text { observation as the omitted category. }\end{array}$ \\
\hline Primary education & Reference \\
\hline Secondary education & 1 if individual has secondary education, 0 otherwise \\
\hline Post-secondary education & 1 if individual has post-secondary education, 0 otherwise \\
\hline Year\# Secondary education & $\begin{array}{l}\text { Secondary education indicator interacted with the year } \\
\text { indicators (first year omitted). }\end{array}$ \\
\hline Year\# Post-secondary education & $\begin{array}{l}\text { Post-secondary education indicator interacted with the year } \\
\text { indicators (first year omitted). }\end{array}$ \\
\hline Immigrant\# Secondary education & $\begin{array}{l}\text { Secondary education indicator interacted with the indicator for } \\
\text { immigrant }\end{array}$ \\
\hline Immigrant\# Post-secondary education & $\begin{array}{l}\text { Post-secondary education indicator interacted with the indicator } \\
\text { for immigrant }\end{array}$ \\
\hline Married & 1 if married, 0 otherwise \\
\hline Immigrant\# Married & Married indicator interacted with the indicator for immigrant \\
\hline County & County of residence. 23 indicators (one county is omitted). \\
\hline Children 0-3 & Number of children in ages $0-3$ years. Continuous \\
\hline Children 4-6 & Number of children in ages $4-6$ years. Continuous \\
\hline Children $7-10$ & Number of children in ages $7-10$ years. Continuous \\
\hline Children 11-15 & Number of children in ages $11-15$ years. Continuous \\
\hline Children $16-17$ & Number of children in ages $16-17$ years. Continuous \\
\hline Immigrant\# Children $0-3$ & Children 0-3 interacted with the indicator for immigrant \\
\hline Immigrant\# Children 4-6 & Children 4-6 interacted with the indicator for immigrant \\
\hline Immigrant\# Children $7-10$ & Children 7-10 interacted with the indicator for immigrant \\
\hline Immigrant\# Children 11-15 & Children $11-15$ interacted with the indicator for immigrant \\
\hline Immigrant\# Children 16-17 & Children 16-17 interacted with the indicator for immigrant \\
\hline Local unemployment rate & $\begin{array}{l}\text { Share unemployed in the municipality of residence, measured } \\
\text { yearly }\end{array}$ \\
\hline Immigrant\# Local unemployment rate & $\begin{array}{l}\text { Local unemployment rate interacted with the indicator for } \\
\text { immigrant }\end{array}$ \\
\hline
\end{tabular}




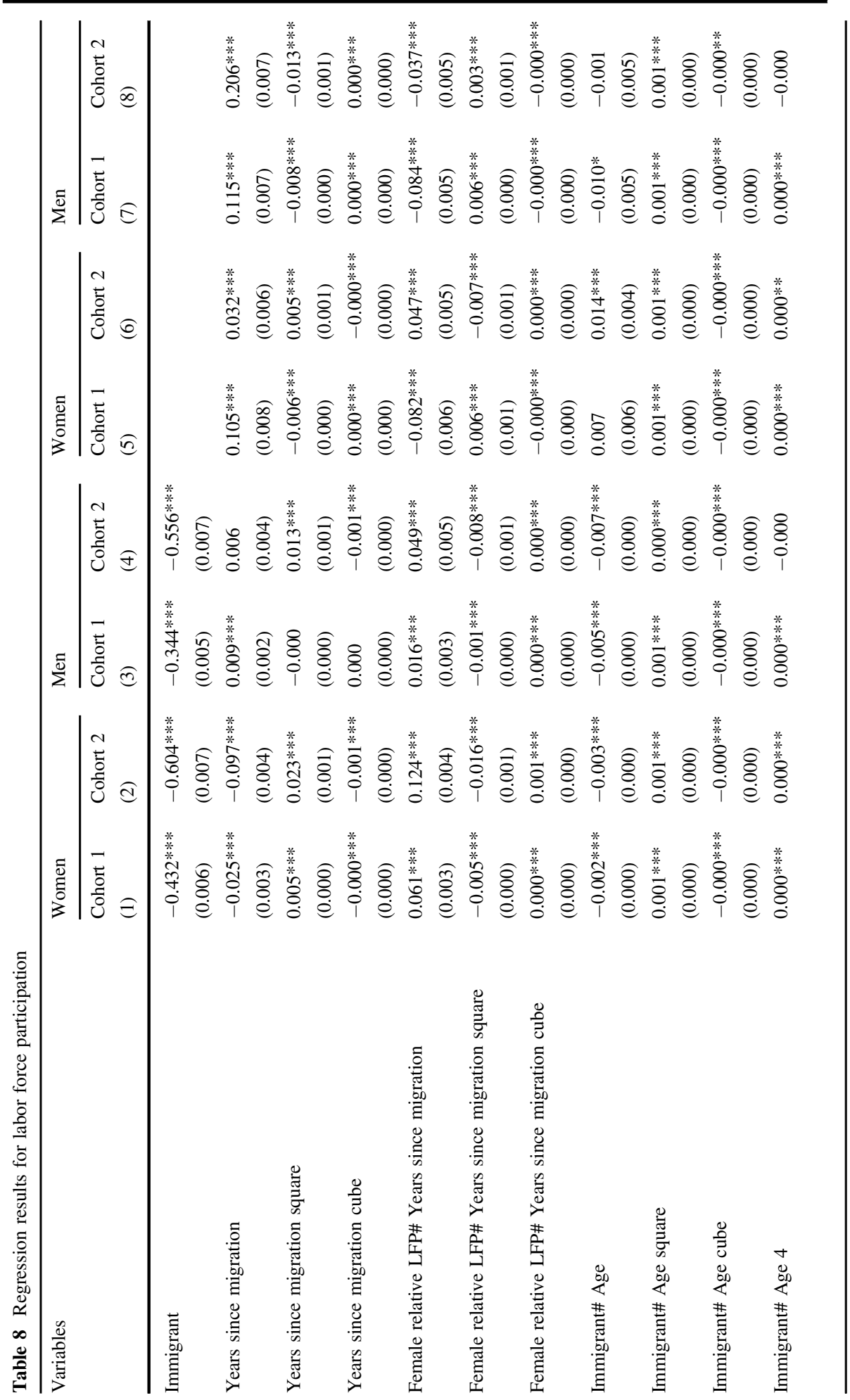




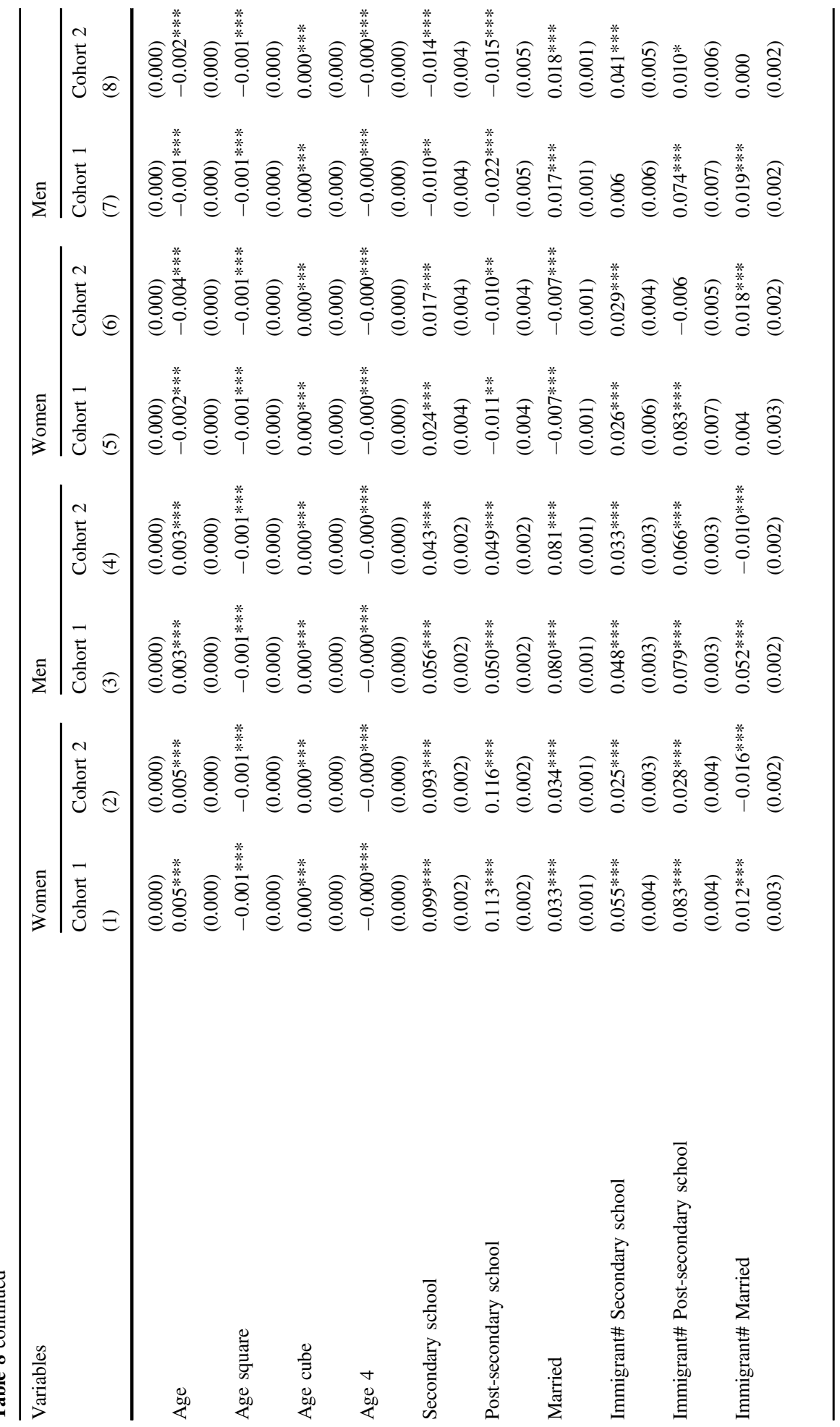




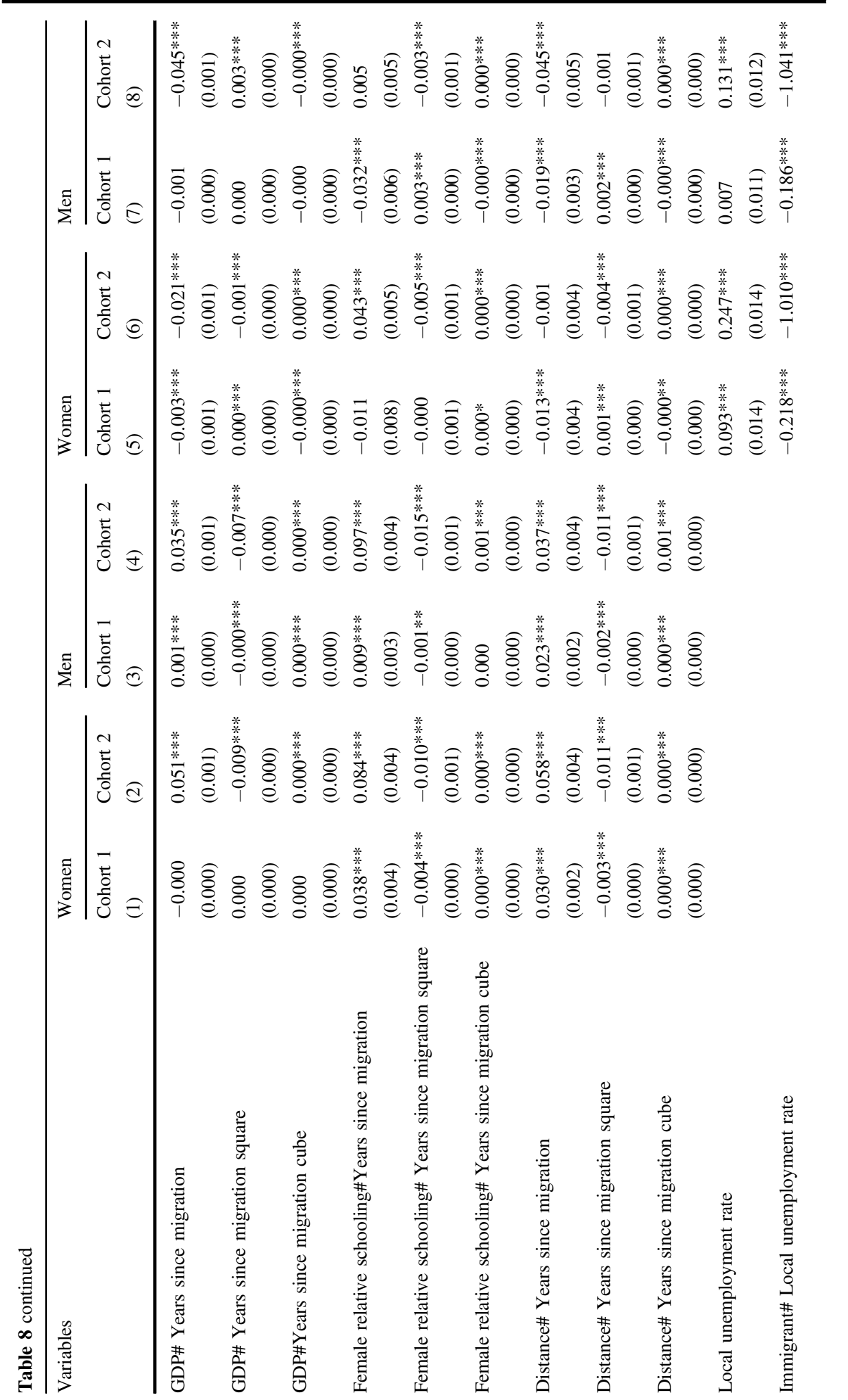




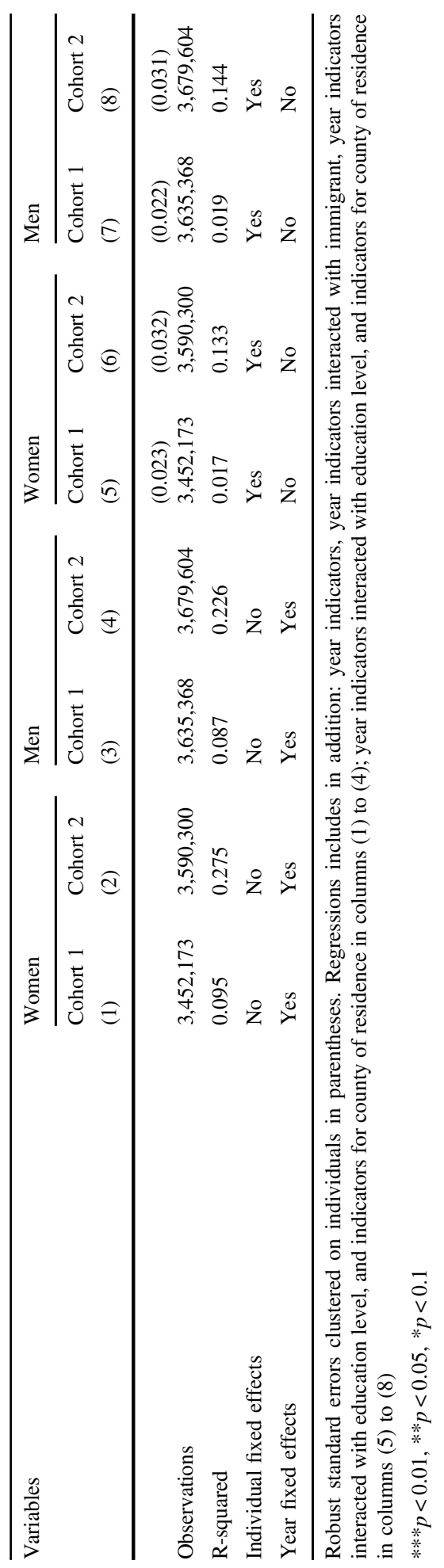




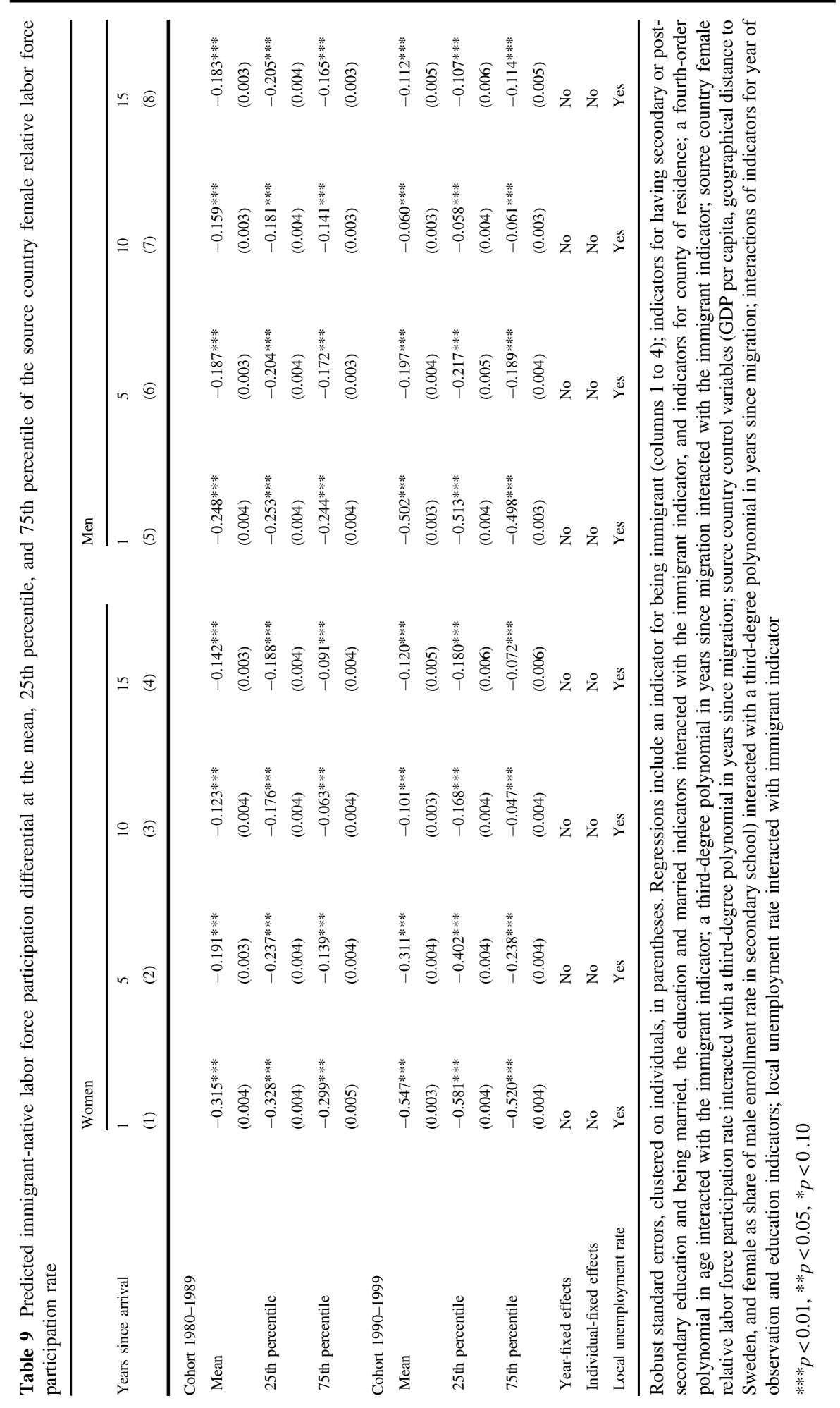




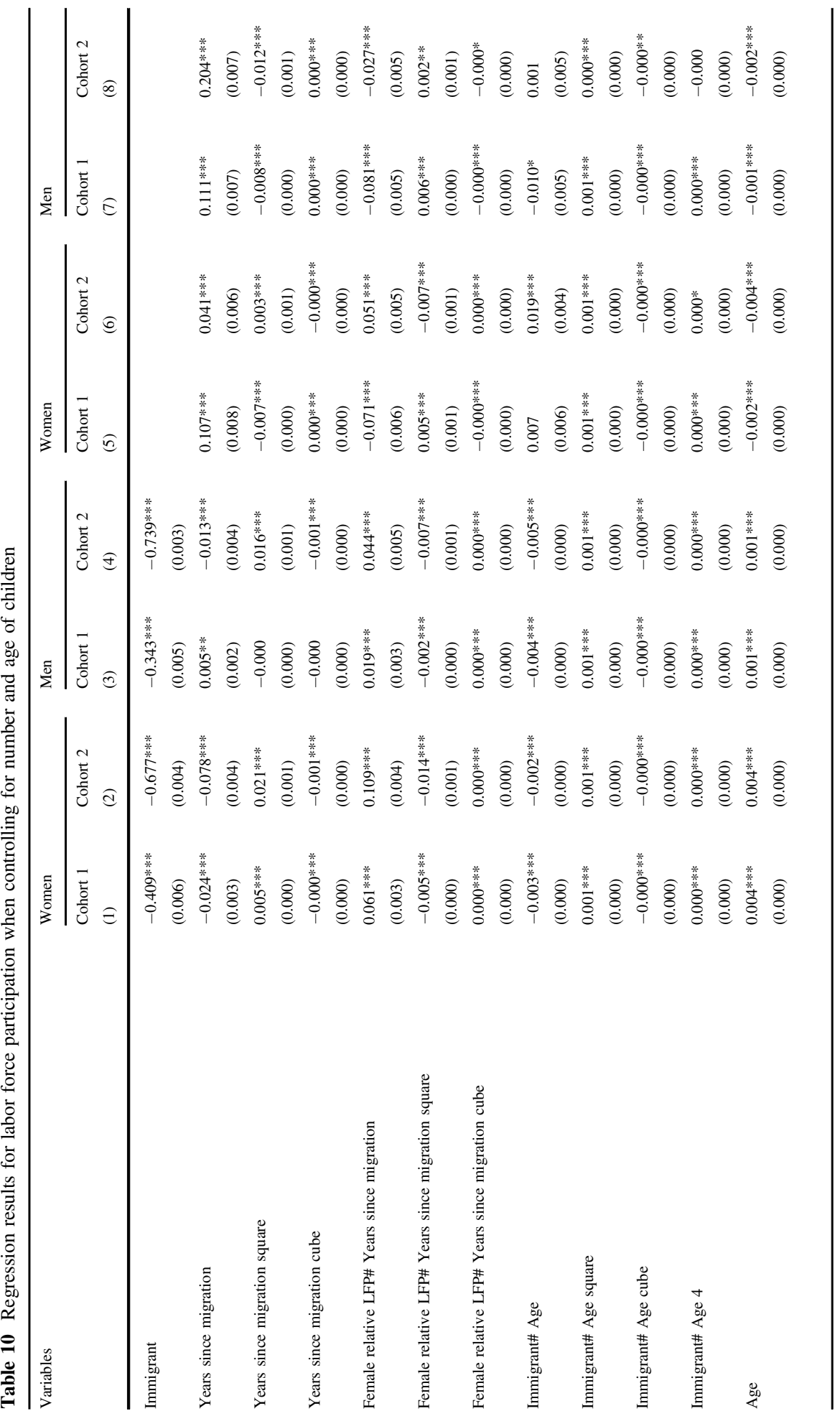




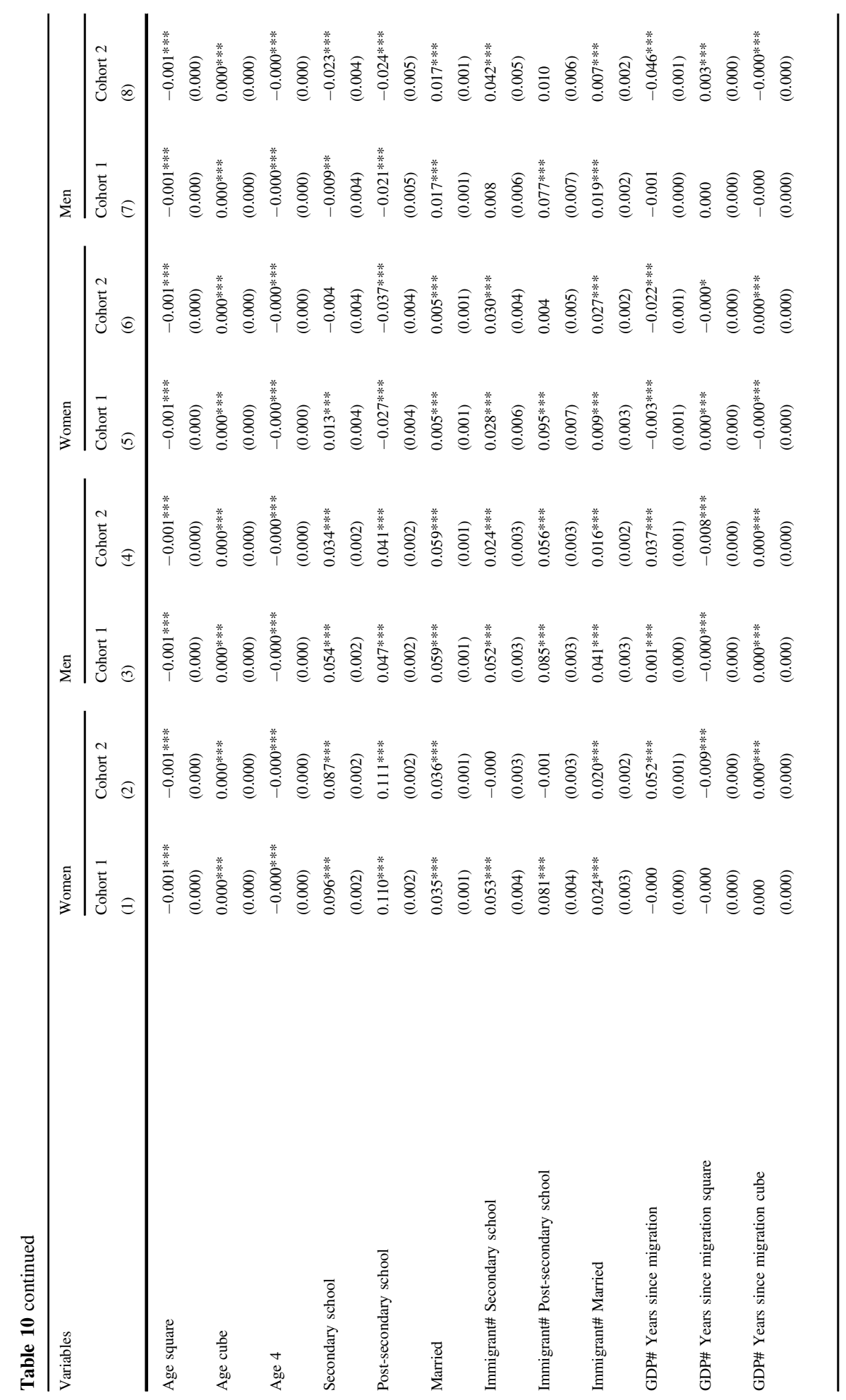




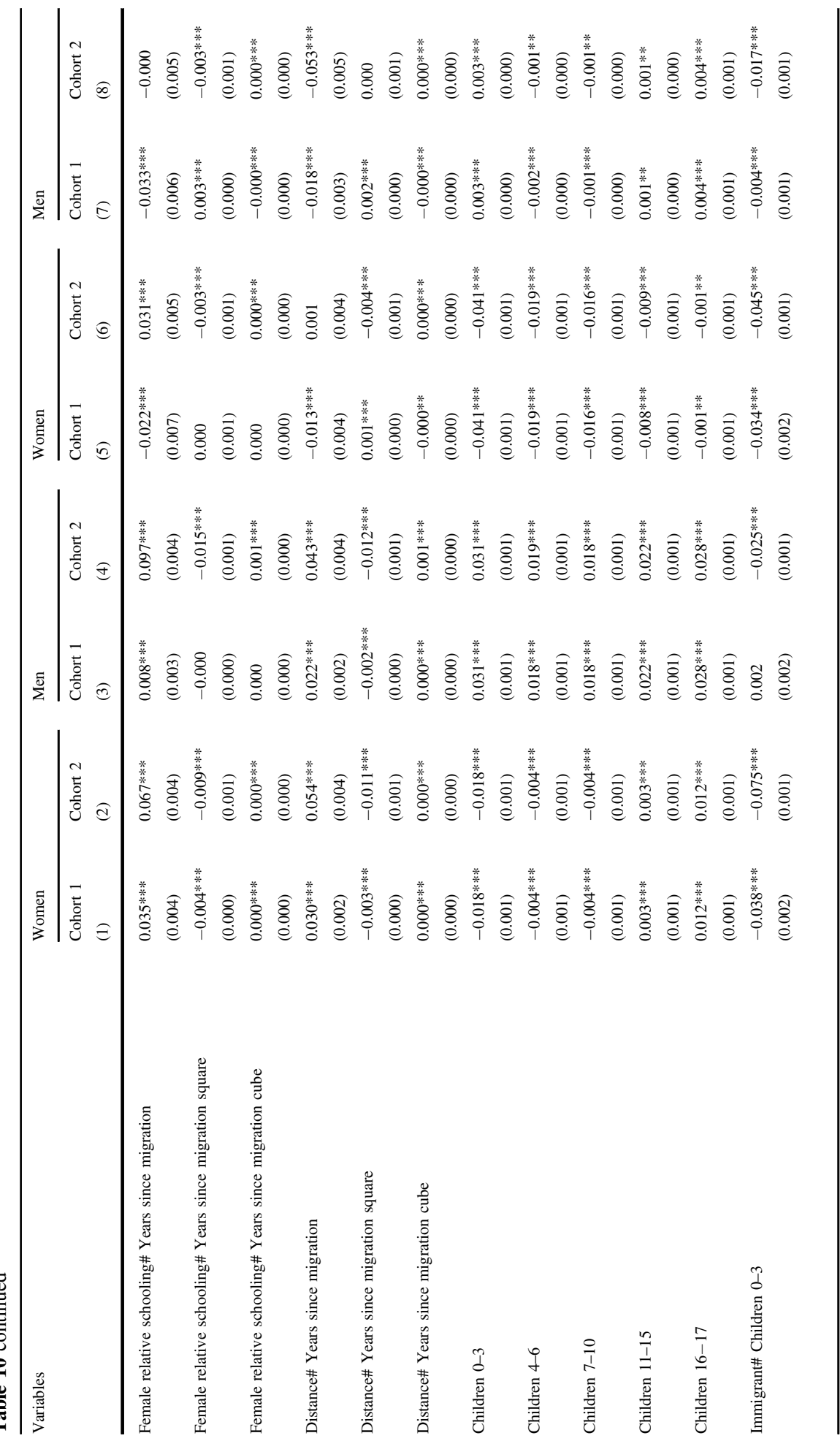




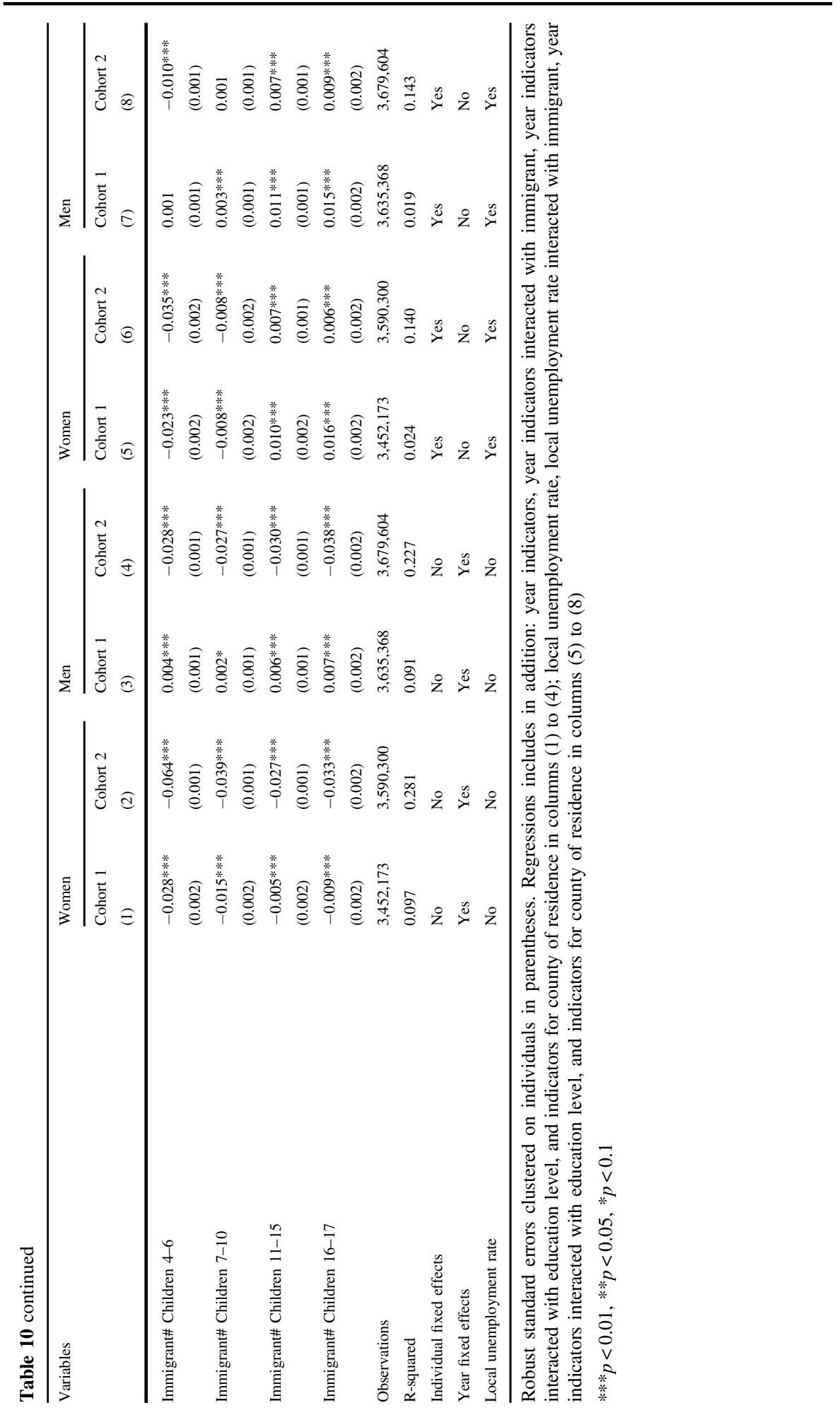


Open Access This article is distributed under the terms of the Creative Commons Attribution 4.0 International License (http://creativecommons.org/licenses/by/4.0/), which permits use, duplication, adaptation, distribution, and reproduction in any medium or format, as long as you give appropriate credit to the original author(s) and the source, provide a link to the Creative Commons license, and indicate if changes were made.

\section{References}

Acharya, S. (1996). Women in the Indian Labour Force. A temporal and spatial analysis. In: Horton, Susan. (Ed.) Women and Industrialization in Asia. London: Routledge.

Aigner, D. J., \& Cain, G. G. (1977). Statistical theories of discrimination in labor markets. Industrial and Labor Relations Review, 30(2), 175-187.

Albrecht, J. W., Björklund, A., \& Vroman, S. B. (2003). Is there a glass ceiling in Sweden? Journal of Labor Economics, 21(1), 145-177.

Albrecht, J. W., Edin, P. A., \& Vroman, S. B. (2000). A cross-country comparison of attitudes towards mothers working and their actual labor market experience. Labour, 14(4), 591-607.

Andersson, L. (2011). The Female Immigrant Labour Supply: The Effect of an In-work Benefit. Labour, 25(2), 198-227.

Antecol, H. (2000). An examination of cross-country differences in the gender gap in labor force participation rates. Labour Economics, 7(4), 409-426.

Antecol, H. (2001). Why is there interethnic variation in the gender wage gap?: The role of cultural factors. Journal of Human Resources, 36(1), 119-143.

Anxo, D., Mencarini, L., Pailhé, A., Solaz, A., Tanturri, M. T., \& Flood, L. (2011). Gender differences in time use over the life course in France, Italy, Sweden, and the US. Feminist Economics, 17(3), 159-195.

Becker, G. S. (1957). The Economics of Discrimination. Chicago: The University of Chicago Press.

Becker, G. S. (1985). Human capital, effort, and the sexual division of labor. Journal of Labor Economics, 3(1), 33-58.

Beenstock, M., Chiswick, B. R., \& Paltiel, A. (2010). Testing the immigrant assimilation hypothesis with longitudinal data. Review of Economics of the Household, 8(1), 7-27.

Blau, F. D. (1992). The fertility of immigrant women: Evidence from high fertility source countries. In G. J. Borjas \& R. B. Freeman (Eds.), Immigration and the Workforce: Economic Consequences for the United States and Source Areas (pp. 93-134). Chicago: The University of Chicago Press.

Blau, F. D. (2015). Immigrants and gender roles: assimilation vs. culture. IZA Journal of Migration, 4(23), $1-21$.

Blau, F. D., \& Kahn, L. M. (1996). Wage structure and gender earnings differentials: An international comparison. Economica, 63(250), 29-62.

Blau, F. D., \& Kahn, L. M. (2000). Gender differences in pay. Journal of Economic Perspectives, 14(4), 75-99.

Blau, F. D., \& Kahn, L. M. (2015). Substitution between individual and source country characteristics: Social capital, culture, and US labor market outcomes among immigrant women. Journal of Human Capital, 9(4), 439-482.

Blau, F. D., Kahn, L. M., Liu, A. Y., \& Papps, K. L. (2013). The transmission of women's fertility, human capital, and work orientation across immigrant generations. Journal of Population Economics, 26(2), 405-435.

Blau, F. D., Kahn, L. M., \& Papps, K. L. (2011). Gender, source country characteristics, and labor market assimilation among immigrants. Review of Economics and Statistics, 93(1), 43-58.

Borjas, G. J. (1987). Self-selection and the earnings of immigrants. American Economic Review, 77(4), 531-553.

Borjas, G. J. (1995). Assimilation and changes in cohort quality revisited: What happened to immigrant earnings in the 1980s? Journal of Labor Economics, 13(2), 201-245.

Barth, E., Bratsberg, B., \& Raaum, O. (2004). Identifying earnings assimilation of immigrants under changing macroeconomic conditions. Scandinavian Journal of Economics, 106(1), 1-22.

Bratsberg, B., Raaum, O., \& Røed, K. (2014). Immigrants, labour market performance and social insurance. Economic Journal, 124(580), 644-683.

Bredtmann, J. \& Otten, S. (2013). The role of source- and host-country characteristics in female immigrant labor supply. MPRA Working Paper No. 44544.

Carlsson, M. (2011). Does hiring discrimination cause gender segregation in the Swedish labor market? Feminist Economics, 17(3), 71-102. 
Charles, M. \& Grusky, D. B. (Eds.) (2004). Occupational ghettos. The worldwide segregation of women and men. Stanford: Stanford University Press.

Damas de Matos, A. (2017). Firm heterogeneity and immigrant wage assimilation. Applied Economics Letters, 24(9), 653-657.

Edin, P. A., LaLonde, R. J., \& Åslund, O. (2000). Emigration of immigrants and measures of immigrant assimilation: Evidence from Sweden. Swedish Economic Policy Review, 7(2), 163-204.

Eliasson, T. (2014). Empirical essays on wage setting and immigrant labor market opportunities. Uppsala, Sweden: Department of Economics, Uppsala University. Doctoral dissertation.

England, P. (1992). Comparable worth. Theories and evidence. New York, NY: Aldine de Gruyter.

Esping-Andersen, G. (1990). The three worlds of welfare capitalism. Cambridge: Polity.

Eylem Gevrek, Z., Gevrek, D., \& Gupta, S. (2013). Culture, intermarriage, and immigrant women's labor supply. International Migration, 51(6), 146-167.

Fernández, R. (2007). Alfred Marshall lecture women, work, and culture. Journal of the European Economic Association, 5(2-3), 305-332.

Fernández, R. (2008). Culture and economics. In S. N. Durlauf \& L. E. Blume (Eds.), New Palgrave Dictionary of Economics. Basingstoke: Palgrave Macmillan.

Fernández, R., (2011). Does culture matter? In J. Benhabib, M. O. Jackson, \& A. Bisin (Eds.), Handbook of Social Economics. Amsterdam: North-Holland, 482-508.

Fernández, R., \& Fogli, A. (2009). Culture: An empirical investigation of beliefs, work, and fertility. American Economic Journal: Macroeconomics, 1(1), 146-177.

Finseraas, H., \& Kotsadam, A. (2017). Ancestry culture and female employment-An analysis using second-generation siblings. European Sociological Review, 33(3), 382-392.

Fortin, N. M. (2005). Gender role attitudes and the labour-market outcomes of women across OECD countries. Oxford Review of Economic Policy, 21(3), 416-438.

Gustafsson, B., \& Zheng, J. (2006). Earnings of immigrants in Sweden, 1978 to 1999. International Migration, 44(2), 79-117.

Hammarstedt, M. (2003). Income from work among immigrants in Sweden. Review of Income and Wealth, 49(2), 185-203.

Hausmann, R., Tyson, L. D. \& Zahidi, S. (Various years). The global gender gap report. Geneva: World Economic Forum.

Hwang, J. (2016). The second shift: assimilation in housework time among immigrants. Review of Economics of the Household, 14(4), 941-959.

International Labour Organisation. LABORSTA. http://laborsta.ilo.org/. Accessed Apr 2014.

International Labour Organisation. ILOSTAT. http://www.ilo.org/ilostat. Accessed Jan 2017.

Lundh, C., \& Ohlsson, R. (1999). Från arbetskraftsimport till flyktinginvandring. Stockholm: SNS.

Lubotsky, D. (2007). Chutes or ladders? A longitudinal analysis of immigrant earnings. Journal of Political Economy, 115(5), 820-867.

Nekby, L. (2006). The emigration of immigrants, return vs onward migration: evidence from Sweden. Journal of Population Economics, 19(2), 197-226.

Nollenberger, N., Rodríguez-Planas, N., \& Sevilla, A. (2016). The math gender gap: The role of culture. American Economic Review, 106(5), 257-261.

Rønsen, M., \& Sundström, M. (2002). Family policy and after-birth employment among new mothers-A comparison of Finland, Norway and Sweden. European Journal of Population, 18(2), 121-152.

Ruhm, C. J. (1998). The economic consequences of parental leave mandates: Lessons from Europe. Quarterly Journal of Economics, 113(1), 285-317.

Sarvimäki, M. (2011). Assimilation to a welfare state: Labor market performance and use of social benefits by immigrants to Finland. Scandinavian Journal of Economics, 113(3), 665-688.

Statistics Sweden. (2016). The labour market for men and women during the years 2001-2016. http:// www.scb.se/Statistik/AM/AM0401/2016K01J/AM0401_2016K01J_SM_AM110SM1602.pdf. Accessed Jan 2017.

The World Bank. World data bank: Gender statistics. http://databank.worldbank.org/Data/Views/Varia bleSelection/SelectVariables.aspx ?source=283. Accessed Apr 2014.

The World Bank. Educational attainment data, 1960-1985. http://go.worldbank.org/HKOH13Y5D0. Accessed Mar 2015.

The World Bank. Data: GDP per capita. http://data.worldbank.org/indicator/NY.GDP.PCAP.CD. Accessed Mar 2015.

Vella, F. (1994). Gender roles and human capital investment: The relationship between traditional attitudes and female labour market performance. Economica, 61(242), 191-211. 